TI 2013-079/I

Tinbergen Institute Discussion Paper
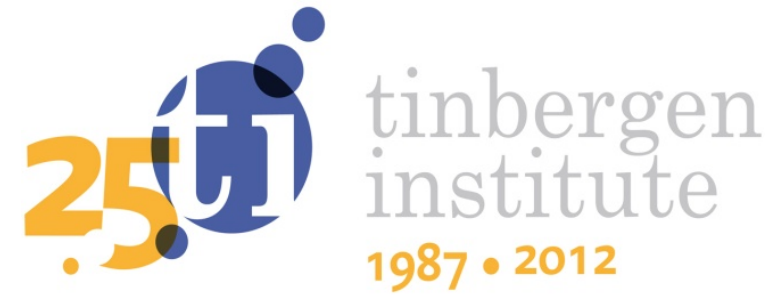

\title{
Other-regarding Preferences, Group Identity and Political Participation: An Experiment
}

Pedro Robalo

Arthur Schram

Joep Sonnemans 
Tinbergen Institute is the graduate school and research institute in economics of Erasmus University Rotterdam, the University of Amsterdam and VU University Amsterdam.

More TI discussion papers can be downloaded at http://www.tinbergen.nl

Tinbergen Institute has two locations:

Tinbergen Institute Amsterdam

Gustav Mahlerplein 117

1082 MS Amsterdam

The Netherlands

Tel.: +31(0)205251600

Tinbergen Institute Rotterdam

Burg. Oudlaan 50

3062 PA Rotterdam

The Netherlands

Tel.: +31(0)10 4088900

Fax: $+31(0) 104089031$

Duisenberg school of finance is a collaboration of the Dutch financial sector and universities, with the ambition to support innovative research and offer top quality academic education in core areas of finance.

DSF research papers can be downloaded at: http://www.dsf.nl/

Duisenberg school of finance

Gustav Mahlerplein 117

1082 MS Amsterdam

The Netherlands

Tel.: +31(0)20 5258579 


\title{
Other-regarding Preferences, Group Identity and Political Participation: an experiment.
}

\author{
Pedro Robalo, Arthur Schram, Joep Sonnemans \\ University of Amsterdam (CREED) and Tinbergen Institute
}

\begin{abstract}
We experimentally study the relationship between other-regarding preferences, group identity and political participation. In doing so, we propose a novel group identity induction procedure that succeeds in creating environments where in-group bias is either high or low. At the individual level, we find that both altruistic subjects and group identifiers participate above average. The most competitive subjects participate much less often than other types, while the most altruistic subjects manage to sustain high participation levels. At the aggregate level, we observe only few statistically significant differences between environments where group identity is high and low. This suggests that the higher participation observed in field settings for close-knit (political) groups might be due to underlying mobilization processes rather than a heightened sense of group-belonging.
\end{abstract}

KEYWORDS: Group identity, Other-regarding preferences, Political participation, Participation Game, Experiment.

JEL CODES: $\quad$ A13, C91, C92, D72.

Please address correspondence to: Pedro Robalo, CREED, Amsterdam School of Economics, Roetersstraat 11, 1018 WB Amsterdam, the Netherlands.

Email: Robalo: p.robalo@uva.nl; Schram: Schram@uva.nl; Sonnemans: j.h.sonnemans@uva.nl.

\section{Acknowledgments}

For their useful comments, we would like to thank Jens Grosser, Georg Kirchsteiger, Botond Koszegi, Jean-Robert Tyran, and seminar participants at IMEBE 2011, Barcelona; MBEES 2011, Maastricht University; CCC 2011, University of Nottingham; the CREED-CESS Meeting 2011, New York University; the $5^{\text {th }}$ NYU-CESS Experimental Political Science Conference, New York University; the Tinbergen Institute, Amsterdam; the Economic Science Association Conference 2012, New York; the $6^{\text {th }}$ Meeting of the Portuguese Economic Journal, University of Porto; the Institute for Advanced Study, Princeton University. Financial support by the priority research area Behavioral Economics of the University of Amsterdam is gratefully acknowledged. Robalo acknowledges financial support from Fundação para a Ciência e Tecnologia through Grant SFRH/BD/43843/2008. 
"Each person wants to participate and at the same time to be left alone. And because it is not possible to have it both ways, there is always a conflict." ${ }^{1}$

Thomas Bernhard, Aus Gesprächen mit Thomas Bernhard (1991)

\section{Introduction}

In June 2012, the Spanish village of Guijo de Galisteo held an unusual referendum. Located in a region where unemployment rates topped $30 \%$, the mayor decided to let the population choose how to use the 15,000 Euro of the municipality budget traditionally allocated to summer festivities: either fund a series of bullfights or create new jobs. Typically, a minority of Spanish citizens appreciates bullfighting. ${ }^{2}$ Yet, with a recorded turnout of $24 \%$ (in an electorate of 1764 voters), bullfight partisans outvoted the supporters of job creation by a margin of approximately 14 percentage points. We thus conjecture that supporters of the bullfight proposal turned out at a higher rate than those in favor of spending the money on job creation. What could cause such a difference in turnout?

Consider what may have motivated citizens to go out and vote in this referendum. Think first about the citizens who support the proposal to spend the money on job creation. A motivation to make the effort to vote may be that one is unemployed, but it is also possible that employed voters wish to aid their fellow unemployed citizens. In other words, pro-job voters may have decided to cast a vote either out of self-interest or as a consequence of otherregarding preferences. Hence, individual preferences may affect the decision to vote or abstain. On the other hand, it seems less straightforward to attribute casting a vote in favor of bullfights to other-regarding preferences. One may however speculate that the bullfight partisans participated in higher numbers due to a relatively higher sense of group identity, irrespective of their motivation. If a sense of group identity provides a motivation to go out and vote, a minority may manage to outnumber the majority at the polls.

As illustrated by this example, field data are likely to provide us with interesting case studies. Yet, though we may 'conjecture' that bullfight supporters voted at higher rates and that they have a sense of group identity, our conclusions are likely to be muddled by unobservability and endogeneity problems. Moreover, the arguments put forward with respect to preference types and group identity are interrelated. A careful study of these issues calls for more control than is available in the field. This paper investigates the issues raised in this example using an experimental framework.

A referendum like the one in Guijo de Galisteo is just one of many ways in which democratic politics provide a peaceful solution to disputes between groups with diverging interests. Had there not been a referendum the groups supporting and opposing money spending on

\footnotetext{
${ }^{1}$ This translation is borrowed from Alexander Düttmann, to whom we're thankful for providing us with the original German reference (Hofmann 1991).

${ }^{2}$ A 2008 poll by the newspaper El País finds that only 37\% of the Spanish claim to appreciate bullfights (http:// elpais.com/diario/2010/08/01/espana/1280613602_850215.html). Approval rates are relatively homogenous across Spanish regions (http://www.columbia.edu/itc/spanish/cultura/texts/Gallup_CorridasToros_0702.htm).
} 
bullfights could have, for example, developed lobbies aimed at affecting the mayor's decision or they could have organized public gatherings and demonstrations. A group's success in such political activities depends on many factors. As documented by the above example, one important element is the extent to which it manages to mobilize its members to participate in political endeavors (Leighley 2001). Participation could involve, for example, voting in the referendum, contributing effort or funds to the lobby, or showing up at the demonstration. Often, the group with the highest level of participation (for example, the highest turnout rate in a referendum) is most likely to be politically successful, and therefore has a high probability of success in conflicts with other groups. ${ }^{3}$ Hence, member participation in a group's effort is important.

This paper studies such participation in the context of an interaction between groups competing for benefits. We address the question of how this participation is affected by the interaction between the two elements introduced in the example. These are, on the one hand, a sense of group identity that members may have and, on the other hand, the extent to which members have preferences that take into account the well-being of others. This is an important question because the outcome of group conflicts can have severe consequences for the members of the groups concerned, irrespective of an individual member's decision to participate in it. If certain individuals or groups participate more than others, this might bias policies in a direction that is not representative of the majority's preferences. If, for example, altruists participate more, policies may develop that are perceived to be more 'altruistic'. Or, if some groups manage to create a stronger feeling of group identity than others, this could put them in an advantageous position that is unrelated to the conflict at hand. Either of these effects could harm the efficient use of an economy's resources because they yield an allocation that is biased towards the preferences of the political participators (see Lijphart 1997 for a similar argument with respect to election turnout).

Individuals facing a decision whether or not to participate in group action typically experience a social dilemma towards their group, i.e., a situation in which the members of the group would be better off if all of them participated (cooperated), but where individual incentives make non-participation (defection) more attractive (Dawes 1980). Examples of social dilemmas in political life include contributions to a lobbying group or showing up at a demonstration: the success of each of these actions is non-decreasing in the extent of participation by group members, but members of the group have an incentive to free-ride on co-members' efforts. Moreover, the situations we focus on involve a conflict with other groups. This competition at the intergroup level might provide the individual with incentives to participate in her group's efforts. A prime example is an election where two factions of an electorate compete for victory: the group with higher participation wins the election and reaps the benefits. In this environment, free-riding may not always be an equilibrium strategy for a rational decision maker (Levine and Palfrey 2007). ${ }^{4}$

\footnotetext{
${ }^{3}$ These arguments also extend to elections for representation in legislative bodies. A group whose members vote at a high rate will have more political power than a group with low turnout, and thus, will be able to better pursue its group interests when legislation is determined.

${ }^{4}$ In particular, Levine and Palfrey (2007) show that in such settings a (quantal response) equilibrium often exists characterized by substantial turnout levels.
} 
We conjecture that the individual participation decision in such environments takes into account the ties that bind the group. Moreover, an individual may more generally take the consequences for others into account when deciding on her actions. In other words, an individual may have other-regarding preferences, but these may be specifically directed towards her group's members and their strength may depend on the extent to which she identifies with the group. How much an individual cares for the individuals in her group and how much she cares about people in the other group are both likely to influence the sacrifices she is willing to make. This paper addresses our conjecture by studying the effect of otherregarding preferences and group identity (and their interaction) on participation in group action.

One important goal of our experimental design is therefore to create environments with distinct levels of group identity, in order to study its influence on individual and aggregate participation. In addition, we want to know whether participation depends on other-regarding motivations, both in general and in interaction with group identity. For this purpose the design includes a measurement of such motivations, using a so-called value orientation test. Finally, we measure political participation by studying individual choices in a participation game (Palfrey and Rosenthal 1983): two groups of equal size compete for benefits, where the probability of winning is increasing in the number of participating subjects in one's group and decreasing in the number of participants in the other group. Hence, our experiment induces distinct levels of group identity, measures other-regarding preferences and allows us to link (combinations of) these variables to political participation.

In order to derive hypotheses on individual and aggregate behavior, we combine insights from a theoretical analysis of the participation game with the available empirical evidence. First, we hypothesize that more other-regarding subjects will participate more often. Second, we expect environments with a high bias towards the in-group to foster fiercer competition, and therefore higher aggregate participation. Third, we hypothesize that subjects who exhibit higher levels of identification with their group will participate more often.

Our results may be summarized as follows. First, they provide support for the hypothesis that individual participation is higher for more altruistic subjects. In particular, we observe that a group of competitive subjects stand out from the rest by abstaining much more often; for the remaining subjects the relationship between their other-regarding preference and political participation is less pronounced. Second, we were successful in inducing distinct levels of ingroup bias across treatments, something that bears methodological relevance given the notorious difficulty of creating group identity in the laboratory (Eckel and Grossman 2005). This allows us to conclude that aggregate participation does not have a statistically significant relationship with group identity in our experiment, even though the relationship is positive, as hypothesized. Third, regarding the individual impact of group identity, individuals who tend to feel more attached to their group in the first place participate more often. Our experimental inducement of further group identity crowds out this relationship, however.

The organization of this paper is as follows. The next section discusses the literature that relates political participation to other-regarding preferences or group identity. Section 3 presents the conceptual analysis of the participation game and derives our hypotheses. 
Section 4 describes our experimental design. In section 5 we present and analyze our data. A final section concludes.

\section{Related Literature}

Both other-regarding preferences and group identification have been the subject of recent attention within the rational choice approach to political participation. This approach has traditionally struggled with the so-called 'paradox of participation' ${ }^{5}$, but has by now uncovered various factors that help explain why rational individuals may participate in a group effort (see Palfrey 2009 for a recent overview).

The addition of other-regarding preferences to the calculus of participation has led to models that escape the prediction of low mobilization. For individuals with such preferences participation becomes instrumentally rational if the benefits derived from one's group winning (which now include the benefits to co-members) are not overcome by the low probability of being pivotal. Models in this vein have been proposed by Jankowski (2002), Edlin et al. (2007), Feddersen et al. (2009), and Evren (2010). There is some field (Knack 1992, Jankowski 2007) and experimental (Fowler 2006, Fowler and Kam 2007, Dawes et al. 2011) evidence supporting a positive relationship between social preferences and participation. Our results add to this stream of evidence by relating a direct measure of an individual's level of other-regarding preferences to the frequency of participation in intergroup competition. Moreover, we contribute with novel evidence on the interaction between an individual's other-regarding concerns and the extent to which she identifies with her co-members. To some extent, this analysis supplements the work conducted by Fowler (2006), who uses a combination of field and experimental data to show that social identity (proxied by party identification) acts as a catalyst on the positive impact of altruistic motivations on political participation. Though the first to interact other-regarding preferences and group identity, Fowler's methodology has some shortcomings that are mainly related to the lack of control, in the field. ${ }^{6}$ Our laboratory control allows us to measure other-regarding preferences and induce group identity in ways that rule out priming and response bias effects that are likely to occur in a situation where measurements are based on survey questions in a political context.

As for group identity, we first note that groups are seen as acting as agents of intentional and unintentional mobilization (e.g., Pollock 1982) and therefore play a crucial role in the study of political participation. In this paper we are especially interested in the impact of different levels of group identification on the spontaneous mobilization of groups. There is a large literature dealing with the relationship between material resources and spontaneous voter mobilization (e.g., the seminal work by Verba and Nie 1972). The empirical literature has established a number of solid findings, such as a positive correlation between income and participation. However, some puzzles remain. For example, the positive correlation between

\footnotetext{
${ }^{5}$ This paradox confronts empirically observed high rates of participation (e.g., in large-scale elections) with the theoretical observation that participation is seemingly irrational.

${ }^{6}$ Fowler uses survey questions regarding election participation, party identification and political knowledge. Subsequently, subjects play a dictator game, either against someone with the same political preference, with a different political preference or an unknown preference. These dictator choices are poorly incentivized, however, with an expected value of 40 -cents. The observed distribution of giving is at odds with recent meta-studies (Engel 2010), but in line with non-incentivized studies. His results show that more generous people do not participate more, but those who are strong party identifiers and also more generous do participate more.
} 
income, education and participation is much weaker for African-American voters, who participate beyond what their socioeconomic status would predict. Leighley and Vedlitz (1999) provide a number of candidate explanations for this phenomenon: psychological resources (e.g. political interest and participation efficacy beliefs), social connectedness, and group identity. All of these explanations have theoretical appeal and have received some empirical support. However, the mechanisms at work are difficult to identify in the field. For example, it is hard to disentangle the effect of group identity from the impact of social connectedness on participation. Do the members of a group voluntarily participate because of their strong sense of group-belonging, or because their environment encourages participation? Moreover, there is a large literature studying the effects of social context and networks on turnout, whose main conclusions are that participative social environments induce higher individual participation (Kenny 1992), and that exposure to similar views within one's social network leads to higher individual participation (Mutz 2002). Notwithstanding, the magnitude of the effect of a citizen's social network on his participation decision is relatively small (Kenny 1992), and social interaction and social pressure mediate the impact of social group membership on individual political behavior.

This overview shows how difficult it is to isolate the effects of group membership on the participation decision. Moreover, social context, social networks and participation behavior might be endogenously determined, making it difficult to elicit the direction of causality. In contrast, an easy and clean test of the group identity effect can be obtained in the controlled laboratory environment. By comparing the behavior of groups that differ only with respect to their sense of group-belonging we can isolate the effect of group identity on participation.

The effects of group identity have been studied within the so-called group identity paradigm, which explores the influence of 'group-belonging' sentiments on how individuals make decisions in instances of intergroup behavior. In short, it studies the influence of the "group in the individual" (Hogg and Abrams 1998). Tajfel (1982) gives two criteria that must be satisfied for group identification to arise; the first is cognitive, and requires that members are aware of group membership; the second is evaluative, in that "awareness is related to some value connotations". Group-based behavior then arises from categorization processes that partition the social world into an 'in-group' and an 'out-group'; relative attachment to the in-group over the out-group (the so-called in-group bias) is then assumed to drive intergroup relations. The body of knowledge on group identity that has developed over the past few decades is quite extensive and has produced a number of robust findings (see Brewer 2007). Recent experimental work has shown that group identity and its salience impacts strategic behavior (Charness et al. 2007) and that individuals tend to be more altruistic towards in-group members (Chen and Li 2009), for example. Our experimental design builds on the accumulated knowledge because it allows us to create an environment where group identity can be induced, measured, and controlled. Moreover, it allows us to investigate the role of group identity in an environment of intergroup competition. To the best of our knowledge, we are the first to do so in a controlled laboratory environment. 


\section{Conceptual Framework and Hypotheses}

We study participation behavior using the game proposed by Palfrey and Rosenthal (1983). This section provides an outline of this framework and the main results that follow from our implementation (Appendix A presents a formal analysis).

Two groups of equal size compete for victory, which depends on participation. All players decide simultaneously (and individually) whether or not to participate, which is costly (c). The group where more players participate, wins. Players on the winning side obtain a monetary payoff $\left(B^{W}\right)$ that is higher than the one accruing to players on the losing side $\left(B^{L}\right)$. In case of a tie the winner is decided by a fair coin toss. The structure and payoffs of the game are common knowledge.

We assume that players have a utility function that allows for other-regarding (altruistic) and group-discriminating components:

$$
U_{i}=u_{i}+\alpha_{i}\left(\beta_{i} \sum_{j \in\left\{G_{i} \backslash i\right\}} U_{j}+\gamma_{i} \sum_{h \in G_{-i}} U_{h}\right)
$$

where $u_{i}$ is the individual payoff, $\alpha_{i}$ is the weight put on other players' welfare, $\beta_{i} \geq 0$ is the weight put on the welfare of players in the same group, $\gamma_{i} \geq 0$ is the weight put on the welfare of players in the other group, $G_{i}$ is player $i$ 's group (the in-group), and $G_{-i}$ is the group against which $i$ 's group competes (the out-group). These preferences express an interdependent utility function which is increasing in other individuals' utilities, but which allow the utility of individuals in the in-group to be given higher weights. We normalize $\beta_{i}$ and $\gamma_{i}$ such that $\beta_{i}+\gamma_{i}=1$, which is possible to obtain from any $\beta_{i}{ }^{\prime}$ and $\gamma_{i}{ }^{\prime}: \beta_{i}=\beta_{i}^{\prime} /\left(\beta_{i}^{\prime}+\gamma_{i}^{\prime}\right)$ and $\gamma_{i}=\gamma_{i}^{\prime} /\left(\beta_{i}^{\prime}+\right.$ $\left.\gamma_{i}^{\prime}\right)$

Define $m$ as the number of other members in $i$ 's group that participate, and $n$ as the number of players in the other group who participate. The expected utility of Participation and Nonparticipation are then:

$E\left[U_{i} \mid\right.$ Participation $]$

$$
\begin{aligned}
& =\operatorname{Pr}[m+1>n] U_{i}^{w}+\operatorname{Pr}[m+1=n] \frac{\left(U_{i}^{w}+U_{i}^{l}\right)}{2}+\operatorname{Pr}[m+1<n] U_{i}^{l}-c \\
& E\left[U_{i} \mid \text { Non - participation }\right] \\
& \quad=\operatorname{Pr}[m>n] U_{i}^{w}+\operatorname{Pr}[m=n] \frac{\left(U_{i}^{w}+U_{i}^{l}\right)}{2}+\operatorname{Pr}[m<n] U_{i}^{l}
\end{aligned}
$$

where $U_{i}^{w}\left(U_{i}^{l}\right)$ is the utility in case of victory (defeat). An equilibrium strategy in this game is simply a probability of participating. In equilibrium, players are indifferent between participating and abstaining, which renders the Nash equilibrium condition: 


$$
\operatorname{Pr}[m=n]+\operatorname{Pr}[m=n-1]=\frac{2 c}{\left(U_{i}^{w}-U_{i}^{l}\right)}
$$

This condition tells us that a subject will participate if the probability that she breaks $(\operatorname{Pr}[m=n])$ or creates $(\operatorname{Pr}[m=n-1])$ a tie, multiplied by the expected benefit, equals the cost of participation. As we can see from [4], for fixed $c$, the equilibria will be a function of the costbenefit ratio, which in turn depends on $\alpha, \beta$ and $\gamma$ (in addition to $B^{w}$ and $B^{l}$, which are also fixed). For example, for a situation where the in-group is preferred to the out-group $(\beta>\gamma)$ the utility difference is increasing in $\alpha$.

For participation games it is customary to derive quasi-symmetric Nash equilibria, i.e. equilibria in which all members of a group employ the same strategy (e.g., Palfrey and Rosenthal 1983, Großer and Schram 2006). Given that our preference structure is richer than in previous studies, it is necessary to derive equilibria in which probabilities may differ across players, however. One problem is that allowing for heterogeneity leads to a multiplicity of Nash equilibria. An alternative is to derive stochastic equilibria, namely a quantal response equilibrium (QRE, McKelvey and Palfrey 1995). QRE is an equilibrium concept which accommodates bounded rationality by allowing players to make mistakes: best-response strategies are played with higher probability, but not with certainty as in a Nash Equilibrium. For participation games, QRE not only helps us select from the multiple Nash Equilibria that result in a setting with preference heterogeneity like ours, but also its predictions have been shown to fit experimental data better than Nash Equilibrium (Goeree and Holt 2005). Appendix A provides details on the QRE calculations for our setting, which we use to inform our hypotheses.

First, consider the relationship between an individual's altruism level (as measured by $\alpha$ ) and her participation decision. Intuitively, we expect individuals with a higher sense of altruism to be more willing to sacrifice themselves for their group, provided they prefer the in-group to the out-group, which is a weak assumption. This is another way of saying that there is more at stake for an individual who values the welfare of others in her group, and therefore stronger altruism will lead to more frequent participation. ${ }^{7}$ The theoretical analysis of the game (cf. Appendix A) indeed provides evidence that the (quantal response) equilibrium level of participation is increasing in other-regarding concerns $(\alpha)$ in a broad parameter range, including parameters that are compatible with our data. The existing empirical evidence provides further support for the conjecture that other-regarding concerns foster individual participation. Relating self-stated motivations to participation game behavior, Schram and Sonnemans (1996b) found that subjects with individualistic goals were less likely to participate, whereas subjects with cooperative goals were more likely to participate. ${ }^{8}$

\footnotetext{
${ }^{7}$ Extremely altruistic individuals, i.e. those who value the welfare of an anonymous person more than their own, may prefer the out-group to win. In such cases, non-participation is the individual best-response. However, such levels of altruism are hardly observed in the laboratory, let alone in the field.

${ }^{8}$ In fact, this is precisely what experimental subjects will tell you. In our experiment, we asked in a postexperimental questionnaire what a subject thought moved a participant who participated often. More than $70 \%$ responded that this was either cooperation towards the in-group or cooperation towards both groups. Moreover, a participant who participated rarely was attributed a selfish motivation by $77.5 \%$ of the subjects. For details, see Table D.1 in Appendix D.
} 
This yields our first hypothesis:

Hypothesis 1: Individual participation is increasing in the level of other-regarding concerns, i.e. more altruistic subjects participate at higher rates.

Next, we consider the effects of group identity on participation. We are mainly concerned whether participation is higher in scenarios where in-group bias is more pronounced. The QRE that we obtain show that aggregate participation is increasing in in-group bias levels. This is supported by the empirical regularities mentioned in the previous section, in particular the fact that in-group favoritism leads to more competitive behavior. We therefore expect higher aggregate participation when group identification is induced. In line with this conjecture, Schram and Sonnemans (1996b) studied the effect of group identity on participation behavior by implementing different matching protocols in a participation game. ${ }^{9}$ They elicit group identity using the minimal group paradigm and find that the effect of group identity is significant, though not pronounced. Moreover, various studies using the participation game framework (Bornstein et al. 1989, Bornstein 1992, Schram and Sonnemans 1996a,b, Goren and Bornstein 2000) have experimentally explored the role of communication within the in-group. We conjecture that the exchange of non-binding promises (cheap talk) between group members reinforces the sense of group identity. These studies have shown that such communication significantly increases participation levels. ${ }^{10}$ This allows us to formulate our second hypothesis:

Hypothesis 2a: Higher in-group bias leads to higher levels of aggregate participation.

We further consider situations where individuals within groups are heterogeneous in terms of their in-group bias. This allows us to address how group identity operates at the individual level. Do subjects who feel more attached to their group participate more often than subjects with lower levels of group identity? The theoretical results show that subjects who identify more with their group will tend to participate with a higher probability in a relevant parameter range. Intuitively, the reason may be that individuals who identify more with their group are more willing to incur sacrifices for it, and therefore participate at higher rates. Our third hypothesis follows:

Hypothesis $\mathbf{2 b}$ : Individual participation is increasing in group identification, i.e. subjects exhibiting higher in-group bias participate at higher rates.

\footnotetext{
${ }^{9}$ The authors implement three treatment conditions which were conceived to yield increasing levels of group identity: i) group composition varied from period to period, and both subject identity and choices were anonymous; ii) group composition remained constant, and both identity and choices were anonymous; iii) group composition remained constant, identity was revealed but choices remained anonymous. Participation in ii) was higher than in i) but also higher than in iii).

${ }^{10}$ It has also been shown that inter-group discussion is successful in promoting overall efficiency, provided intragroup communication is not available. We can infer that group-allegiance supersedes social welfare concerns when intra-group information exchange is the coordination mechanism, and conversely when inter-group discussion is used. In addition, Goren and Bornstein (2000) show that in the absence of communication players associate high participation levels to cooperation towards the in-group and do not associate low levels of participation to intergroup cooperation. In the absence of communication, cooperation towards the in-group dominates overall cooperation for most players.
} 


\section{Experimental Design}

Our experiment is composed of three main blocks, each to be explained in detail below. ${ }^{11}$ In the first block, we measure subjects' other-regarding preference type using a value orientation test commonly referred to as the 'ring test'. This test measures how a subject trades off her own welfare for the welfare of another individual. In the second block we manipulate the group attachment of subjects in order to obtain environments where the in-group bias is either high or low. Additional allocation decisions and survey questions were used to measure the degree of in-group bias. In the third block, subjects interact in the participation game (Palfrey and Rosenthal 1983) explained in the previous section. The value orientation test and the participation game are identical across treatments, whereas the group identity induction procedure varies in order to implement different treatments.

The experimental sessions were run at the CREED laboratory of the University of Amsterdam (UvA). Participants were recruited from the CREED subject pool using an online registration system. The subject pool consists of approximately 2000 students, mainly UvA undergraduates from various disciplines. A total of 160 subjects (44\% of which were female) participated in 8 sessions, which took place in June and October 2011. On average, participants earned 28.5 Euros, which included a show-up fee of 7 Euros. The experiment was programmed and conducted in z-Tree (Fischbacher 2007). Payoffs in the experiment are expressed in tokens, exchanged to Euros at a rate of 0.005 Euros per token. For the first and third block (ring test and participation game) we administer practice questions that check subjects' understanding of the tasks. The typical experimental session lasts around two hours.

We will first describe the two parts that are common to all treatments (see Figure 1 for a diagram showing the sequence of parts in the experiment). The test used to measure otherregarding preferences uses decomposed games (Liebrand 1984), a tool applied by social psychologists to assess an individual's social motives. More precisely, the ring test measures the rate at which an individual trades off own welfare for the welfare of other individuals. For a discussion of this test see Liebrand (1984) and Offerman et al. (1996). The version used in the experiment was proposed by van Dijk et al. (2002). Each participant is anonymously paired with two other participants; her choices affect one of them, and the choices of the other one affects her in an identical way. The two participants with whom a subject is paired remain constant throughout the first part of the experiment, but subjects are informed that identities will not be disclosed at any point during the experiment. The test consists of 32 pairwise dictator choices, each presenting the participant with two alternative own-other allocations of monetary payoffs (see Appendix B for a list of all choices and a snapshot of the first choice). For each pairwise choice the participant has to pick her most preferred allocation. Each of the 32 pairwise choices is shown on the screen, both in text and bar graphics. Participants are informed that they will only learn the earnings or losses from this part of the experiment at the end of the session.

\footnotetext{
${ }^{11}$ See appendix E for a transcript of the instructions.
} 


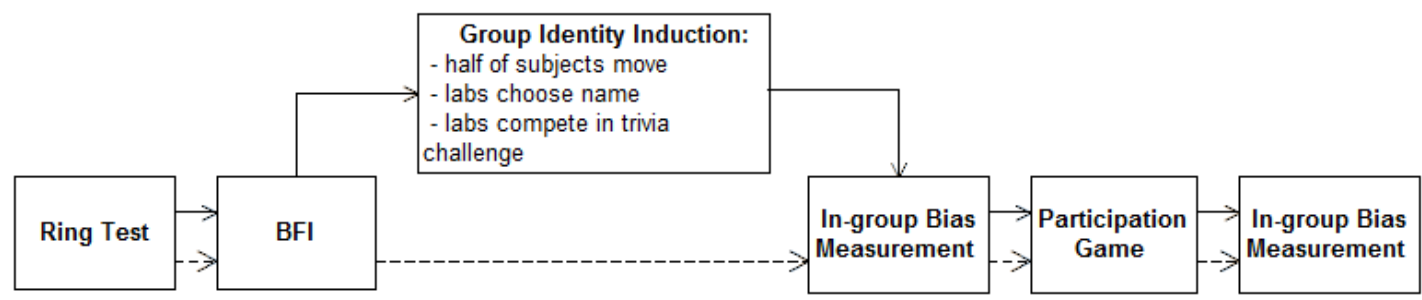

Figure 1 - Sequence in the Experiment.

Notes. Solid lines indicate the sequence in High and Low while dashed lines indicate the sequence in Control. BFI: Big Five Inventory.

For the participation game, individuals are allocated to groups of five participants, with two groups constituting an 'electorate' of ten participants. The parameter values used throughout the second part of the experiment are $B^{W}=120, B^{L}=30$, and $c=30$. Groups remain constant and repeatedly play the game for 40 rounds. At the end of each round, participants are informed of how many others participated in each group, their own earnings (in tokens) in that round, and their cumulative earnings (in tokens) in that part of the experiment.

Our treatments consist of variations in the second part of the experiment, where groups are formed and group identity is induced. A crucial choice concerns the variable (characteristic) used to differentiate between groups. The minimal group paradigm has shown that, in some situations, a mere awareness of belonging to a group, together with group competition for a prize generates behavior consistent with group discrimination (Diehl 1990). In a laboratory setting the minimal group paradigm has not always been successful in producing such results, as pointed out by Charness et al. (2007). For one, the salience of groups in the laboratory, where interaction takes place via computers, is low. In order to induce strong feelings of group identity we therefore need to both differentiate groups along a dimension that matters to subjects and make this difference salient.

The number of potential differentiating variables is quite vast. Political groups may differ along many dimensions, including (but not limited to) ideology, income, education, religion, occupation and race. The relevance of specific variables depends on the political situation one is interested in. For example, opposing groups in a general election may differ along different dimensions than groups on either side of a gun rights rally. To avoid obvious links to specific group conflicts, we distinguish between groups based on a personality trait. We do so for two reasons. First, there is evidence of an increasing influence of such traits on political choices (the so-called 'personalization' of politics; Caprara et al. 2006). Second, a personality trait is a deeply rooted psychological attribute. We expect individuals to care about their personality characteristics, and therefore feel attached to others with shared traits. Our design makes groups salient in ways to be described shortly.

We measure personality traits under the Big Five taxonomy. This framework has shown that factor analysis performed on a multitude of personality data generally recovers five personality characteristics (Openness, Conscientiousness, Extraversion, Agreeableness and Neuroticism). For our inference to be valid, the chosen trait should neither be correlated with other- 
regardingness nor with choices in the participation game. Among the five traits, we believe Openness (receptivity to novel experiences and ideas) complies with these requisites. ${ }^{12}$ The tool we use to measure personality traits is the Big Five Inventory (BFI; John et al. 2008). ${ }^{13}$ The $\mathrm{BFI}$ is a highly validated questionnaire consisting of 44 short sentences, each based on trait adjectives known to be prototypical markers of the Big Five. This test provides a 1-to-5 score of each personality trait.

For all treatment configurations, the group identity induction procedure in the second part of the experiment starts by requesting participants to answer the BFI. Subsequently, they are explained what Openness is and how different Openness scores translate into personal characteristics and behavior. They are also told their own score. This allows us to implement three treatment configurations: high group identity (High), low group identity (Low), and no group identity (Control). All procedures are known to participants.

In the High and Low treatments, the half of the participants whose Openness scores are highest are asked to move to a second laboratory, while the half scoring lowest remain in the laboratory where the experiment started. ${ }^{14}$ After all participants have settled at their new computer stations, they are asked to jointly decide on a name to identify their laboratory. Participants are presented with three pre-determined options. They have the possibility of discussing their choice with the other participants in the same laboratory via a chat interface. Each participant submits a choice, and the most chosen option becomes the name that identifies their laboratory for the remainder of the experiment. Next, the two laboratories compete in a trivia challenge. Each participant is presented with five timed trivia questions; a correct answer is worth one point and an incorrect one is worth zero points. The individual scores are aggregated by laboratory, and the laboratory with the highest score wins 2000 tokens to be equally distributed among its members.

The High and Low treatments differ only with respect to the groups that interact in the participation game (see Figure 2). To start, all members of a group are in the same laboratory. In the High treatment, a group of five participants interacts with a group of five participants drawn from the other laboratory. In the Low treatment, the interacting groups are drawn from the same laboratory. The Control treatment differs from High and Low in that the group identity induction procedure consists of the BFI alone (with an underlying group formation protocol that mimics High). Hence, subjects in the control treatment do not know that they are allocated to groups based on their openness score. ${ }^{15}$

Finally, we use dictator allocation decisions to measure subjects' in-group bias. In particular, we asked each subject to divide 200 tokens between a random participant of his or her group (except himself or herself) and a random participant of the other group. This allocation

\footnotetext{
${ }^{12}$ Table D.2 in Appendix D provides statistical evidence on both relationships. Namely, only Agreeableness seems to be significantly correlated with participation behavior, and no personality trait seems to be significantly correlated with other-regardingness as measured by the ring test.

${ }^{13}$ The BFI cannot be incentivized but we gave 3 Euro to subjects for the time they took to answer it.

${ }^{14}$ The second laboratory room is part of the same laboratory, and therefore is located close-by. Most subjects who stayed in the laboratory room where the experiment started also moved to a different computer station, such that all subjects in each laboratory are seated next to each other (separated by partitions).

${ }^{15}$ Since Openness does not influence participation it does not matter whether the Control session mimics High or Low.
} 
decision was administered twice, just before and just after the participation game. In addition, the final questionnaire included an item for which subjects had to rate, on a 1-10 scale, how attached they felt to their own group and to the other group.
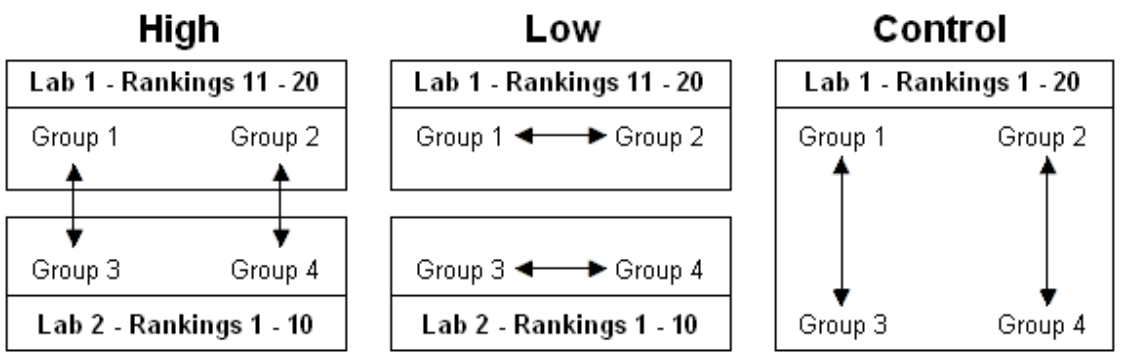

Figure 2- Experimental treatments.

Notes: Arrows indicate competition in the Participation Game.

\section{Experimental Results}

Sub-sections 4.1 and 4.2 present preliminary steps that will aid the analysis of our results, which is carried out in sub-sections 4.3-4.5. In 4.1 we put forward a classification of subjects according to their other-regarding preference type. In section 4.2 we investigate the validity of our group identity manipulation procedure. In 4.3 and 4.4 we present results on bilateral relationships between other-regarding preferences, group identity and participation. These analyses provide partial support for our hypotheses. Stronger support is reported in section 4.5 , where we present a multivariate analysis explaining the participation decision.

\subsection{Subject Classification in Other-Regarding Preferences}

Hypothesis 1 concerns differences in participation behavior across individuals with distinct levels of altruism. To enable this comparison, we divide subjects into categories representing different (kinds of) other-regarding preferences. We start with a brief characterization of our measure. The application of the ring test to measure such preferences presupposes the existence of a motivational vector for each subject. This represents the individual's trade-off between own welfare and the welfare of another in a two-dimensional vector space, where one dimension indexes the own payoff and the other dimension indexes the payoff accruing to the other individual (see Figure 3). Each own-other allocation can be represented by a vector whose origin coincides with the origin of the coordinate system. For each of the 32 pairwise choices in the ring test, an optimizing participant chooses the allocation that is closest to her motivational vector, i.e., it maximizes the projection on this vector. Averaging over an individual's 32 choices yields an approximation of her motivational vector. 


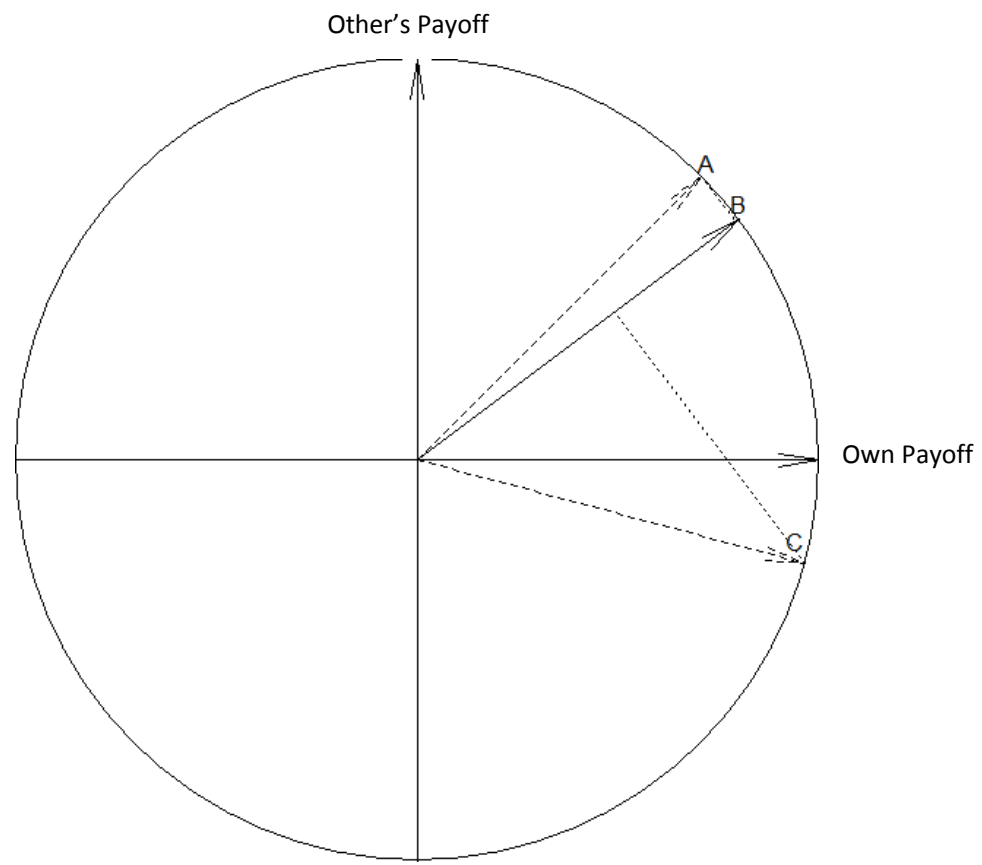

Figure 3-Typical choice in the ring test.

Notes. Suppose B is the motivational vector of a given (rational) subject. When asked to choose between $A$ and $C$, she will choose $A$ as it is closest to her motivational vector (it has the highest projection on it).

A subject's motivational vector can be fully described by its length and direction. Its length can be interpreted as the degree of choice consistency. We will restrict our sample to the 152 subjects (95\%) with a degree of consistency represented by an average vector with length of at least $600 .{ }^{16}$ The slope of the motivational vector - which can also be expressed as the angle formed by the vector and the horizontal axis - describes how the individual trades off own welfare for the welfare of others. For example, one can think of an individual whose vector has an angle of $26.6^{\circ}$ - corresponding to a slope of 0.5 - as someone willing to give away 50 Euro cents to another individual for each Euro she keeps for herself. ${ }^{17}$ The slope of the vector provides a measure of $\alpha$ in equation [1]: the marginal rate of substitution of $i$ 's utility from money for $j$ 's utility. The average angle of the motivational vector in our sample is $6.77^{\circ}$, with a standard deviation of $19.98^{\circ}$; the two widest angles are $-68.93^{\circ}$ and $73.25^{\circ} .{ }^{18}$

The ring test traditionally uses a standard set of categories to classify individuals (Liebrand 1984), assigning to them one of six labels ('aggressive', 'competitive', 'individualistic', 'cooperative', or 'altruistic'). Each corresponds to an area of the circle. One problem with this classification is that it makes for a poor division of data across categories, since individuals

\footnotetext{
${ }^{16}$ In our application of the ring test, each vector (allocation) has a length equal to 1000 . If a subject always chooses the option closest to her (estimated) motivational vector, its length is also 1000 . For comparison, a random sequence of choices yields a motivational vector with length equal to 500 . The same consistency criterion was used by van Dijk et al. (2002).

${ }^{17}$ In our analysis we use the average vector's angle (and not the slope) to represent the value orientation.

${ }^{18}$ This corresponds to an average slope of 0.12 with standard deviation of 0.36 . The steepest slopes are -2.60 and 3.32 .
} 
tend to massively concentrate on the two main categories, 'individualistic' and 'cooperative'. In our sample, $93.13 \%$ of subjects fall within these two categories. We therefore put forward a new classification, which balances a good categorization of the data with an empirically relevant set of categories. This is presented in Table 1 and Figure 4.

Table 1 - Motivational Categories: Definition and Sample Distribution

\begin{tabular}{l|ccc}
\hline & Angle $\left(^{\circ}\right)$ & Slope & \% subjects \\
\hline 1 - Competitive & $<0$ & $<0$ & 19.74 \\
2 - Individualistic & 0 & 0 & 23.03 \\
3 - Weakly Altruistic & $(0,8.53]$ & $(0,0.15]$ & 20.39 \\
4 - Mildly Altruistic & $(8.53,21.8]$ & $(0.15,0.4]$ & 18.42 \\
5 - Strongly Altruistic & $>21.8$ & $>0.4$ & 18.42 \\
\hline Notes. Rows define the motivational categories we distinguish, based on angle \\
(column 2) or slope (column 3) of the estimated motivational vector. The final \\
column shows the distribution of our subjects across these categories. The \\
distribution of subjects across categories per treatment is given in Appendix C \\
(Table C 4)
\end{tabular}

The first category ('competitive') comprises those individuals who are willing to sacrifice part of their gains to decrease the other individual's earnings. The second is composed of individualistic types: subjects whose only motive is to maximize personal gains, regardless of the trade-off imposed on the other. In contrast, altruists are willing to give up some of their personal gains in order to increase the gains of an anonymous other individual. If the rate at which this sacrifice is made is below 0.15 we call them 'weak' altruists; if the rate is between 0.15 and 0.4 we call them 'mild' altruists; and if it is above 0.4 we call them 'strong' altruists. Of course, this classification is no less ad hoc than the standard one. To be sure, a priori there exist no meaningful precise cut-off values to distinguish between motivational categories.

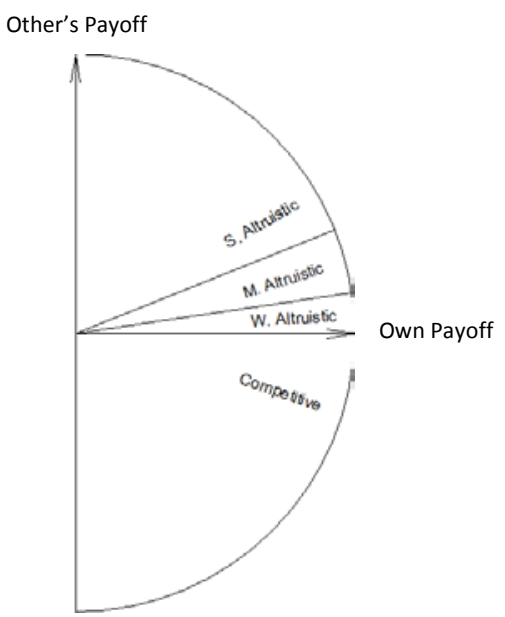

Figure 4 - Motivational categories

Notes. The category 'Individualistic' coincides with the horizontal axis. 


\subsection{Group Identity Induction}

In order to assess the extent to which group identity feelings were successfully induced, and to know how they vary across treatments, we consider measured in-group bias. As explained in the previous section, our measurement of this bias was done in two ways: first, through two dictator allocations of monetary endowments between random members of the in-group and the out-group (one before and one after the participation game); and second, through selfreported attachment to in-group and out-group. Figure 5 presents results from these measures.

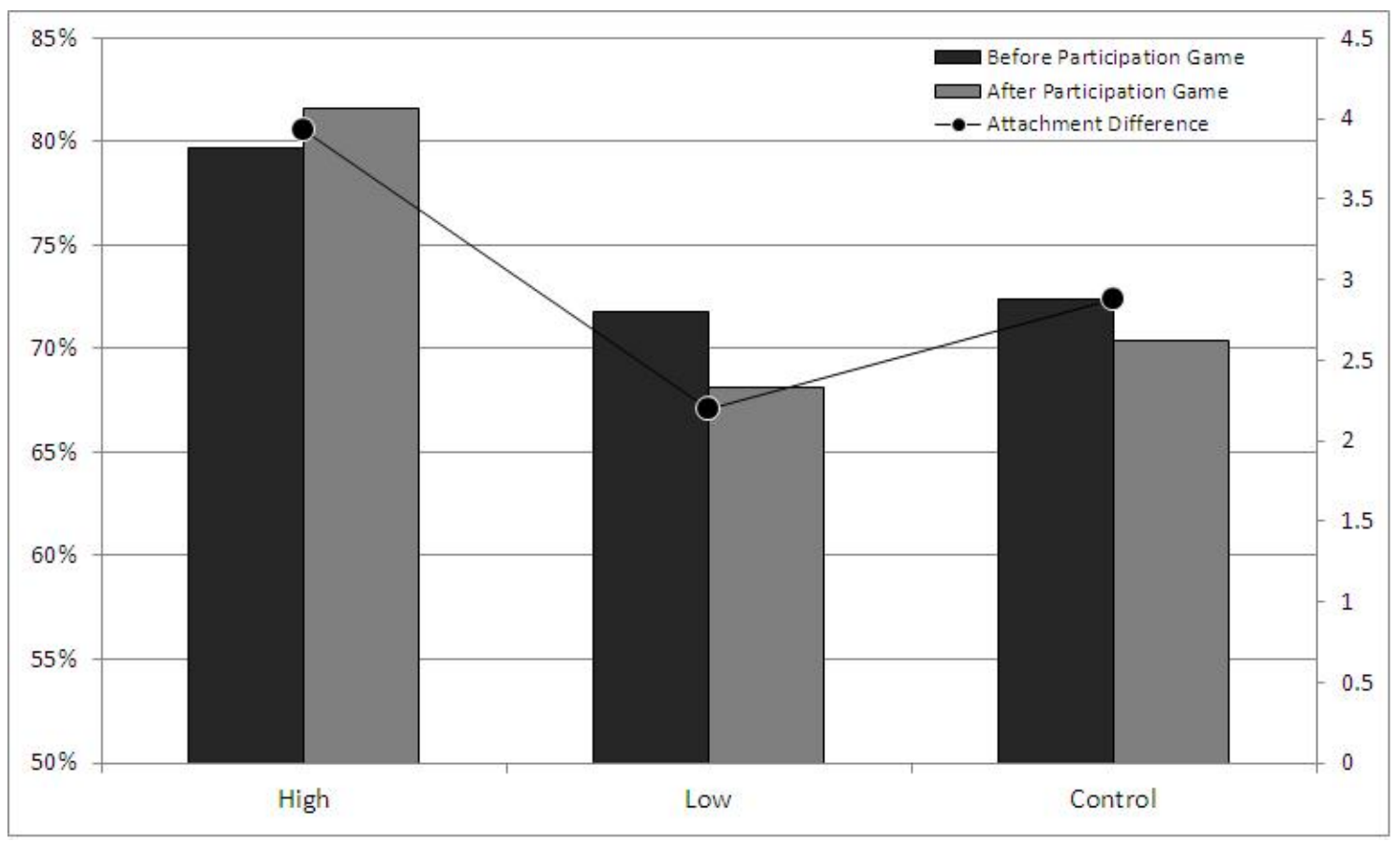

Figure 5 - Group Identity Induction Across Treatments.

Notes. Bars show the fraction of the endowment allocated to the member of the in-group (left axis). Dark gray (light gray) gives the measurement before (after) the participation game. The difference in reported attachment to the own and other groups is given by the connected dots (right axis).

The percentage allocated to the in-group member is highest in the High treatment. This value is (marginally) significantly different than the percentages allocated in the Low and Control treatments, both before ( $\mathrm{MW} \mathrm{p}=0.06$ and $\mathrm{p}=0.08$; $\mathrm{MW}$ hereafter) and after ( $\mathrm{MW} \mathrm{p}=0.10$ and $p=0.03$ ) the Participation Game. The average over the two allocation decisions made by each subject yields significant differences between High and the other two treatments (two-sided Mann-Whitney $U$ test $p=0.01$ and $p=0.03$ for comparisons with Low and Control, respectively). Allocation decisions in the Low treatment are not statistically different from those of the Control treatment ( $\mathrm{MW}, \mathrm{p}>0.75$ for all separate and average comparisons). In the High treatment, a subject allocates approximately $80 \%$ of the total amount to the member of his or her own group before the Participation Game; in the Low and the Control treatments this figure is lower (approximately $72 \%$ ). This pattern widens after groups have interacted in the Participation Game: the average allocation in the High treatment increases to $82 \%$, while in the Low treatment it decreases to $68 \%$ and in the Control treatment to $70 \%$. Allocations before 
and after the Participation Game are not statistically different, neither overall nor for any specific treatment ( $\mathrm{MW}$, all $\mathrm{p}>0.59)$. Finally note that the results for the low and control treatments provide some support for the 'minimal group paradigm' (Tajfel 1982); subjects give more to the (other) own group member than to someone from the other group, even when nu group identity is induced other than by forming the groups based on openness.

The results of the allocation decisions are corroborated by the second indicator of group identity. In the questionnaire, subjects were asked to report their attachment to the in-group and the out-group on a 1 to 10 scale. Computing the difference between these two values yields a measure of self-reported in-group bias on a -10 to 10 scale (see Figure 5). Average stated in-group bias is 3.9 in High, 2.2 in Low, and 2.9 in Control, with standard deviations of 2.87, 3.42, and 4.50, respectively. The difference between High and Low is statistically significant (MW, $\mathrm{p}=0.01$ ), while those between High and Control, and Low and Control, are not (MW, $p=0.37$ and $p=0.27$, respectively).

The purpose of group identity induction was to create distinct levels of group identity between the High and the Low treatments. The results shown in Figure 5 and the corresponding statistical tests show that the procedure used was successful.

This analysis is disaggregated for the different other-regarding preference types in Appendix D. Two questions can naturally be raised: what types are most likely to show a high degree of ingroup favoritism, and what types are more likely to be influenced in their group attachment by interaction in the participation game. In sum, Appendix D yields three main findings about the interaction between other-regarding preferences and in-group bias. First, in aggregate, ingroup bias does not differ across types, except that Competitors are less prone to it than Individualists. Second, the differences in in-group bias we observe across treatments can to a large extent be attributed to altruistic types responding differently to distinct levels of induced group identity. Third, except for Competitors, in-group bias is not affected by the interaction with others in the participation game.

\subsection{Other-regarding Preferences and Participation Behavior}

We now turn to our main research question, which is how political participation is affected by other-regarding preferences and group identity. We start by making the link between motivational vectors and choices in the participation game. Figure 6 presents average participation rates per motivational category throughout the participation game. We observe that competitive individuals clearly participate less often than any other type. The difference between the individual average participation of competitors and any other category is statistically significant (MW $\mathrm{p}<0.01$ for all comparisons). ${ }^{19}$ As for the other categories, it is interesting to note that strong altruists participate less often than the other groups in the first twenty rounds, a tendency that is reversed in the second half of the participation game. Though this pattern is consistent with an initial attempt to lower the aggregate participation in

\footnotetext{
19 Non-parametric tests of type behavior use individual average participation as the observation unit. Nonparametric tests of aggregate behavior use the average participation of a pair of competing groups as the observation unit.
} 


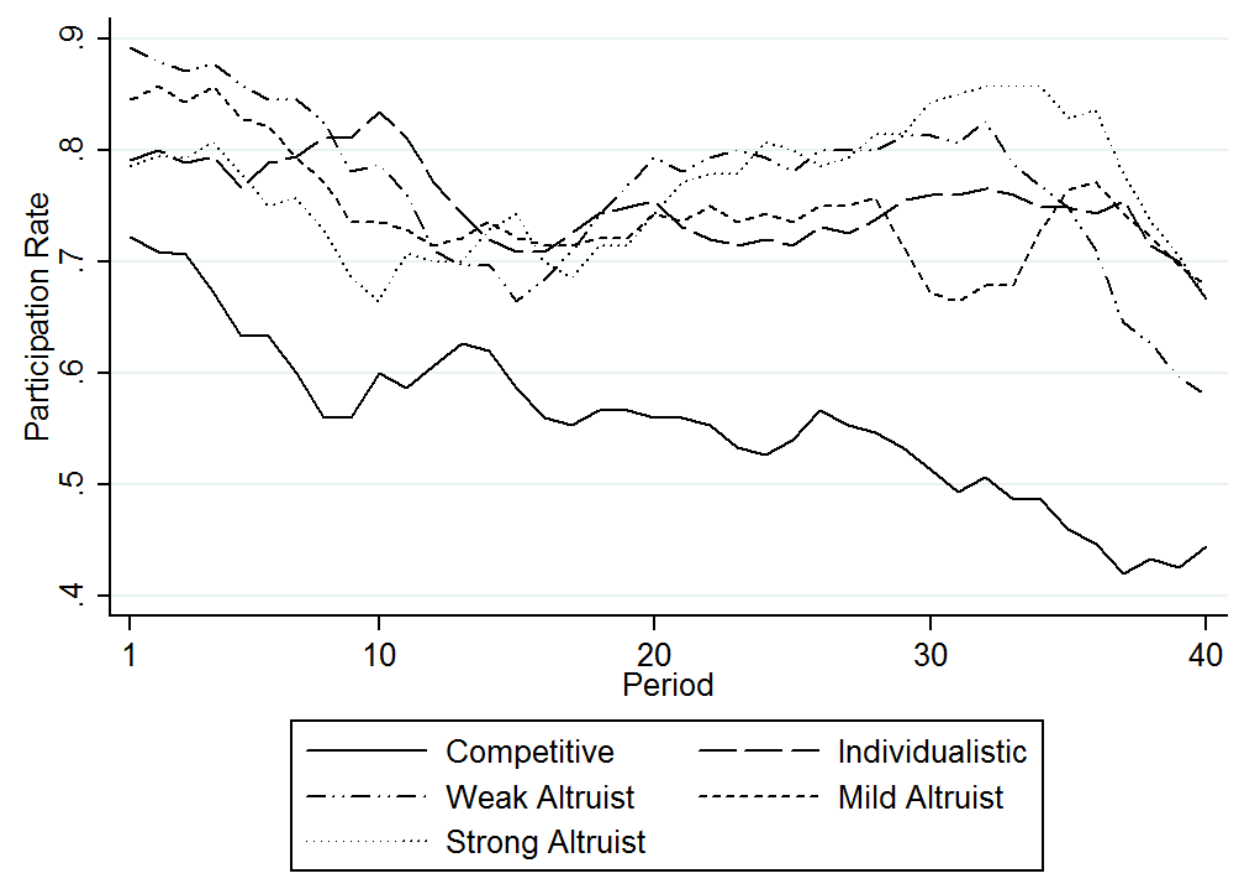

Figure 6 - Evolution of Participation and Motivational Categories.

Notes. Lines connect the average participation rates of participants of a given motivational category, across all group identity treatments. Five-period moving average (two lags, two leads, where available) time series are plotted.

the electorate in order to save on voting costs, the effect is statistically insignificant (there are no statistical differences in any pairwise comparison that does not include competitors).

Consistent with previous evidence, there is a tendency for participation levels to decrease as the game unfolds (e.g. Schram and Sonnemans 1996a). Regressing average participation on a linear trend per motivational category yields a negative and significant relationship for all types except strong altruists, who exhibit a positive, albeit non-significant, increase in participation over time (see Table C.3 in Appendix C). We conclude that strong altruists are the only type succeeding in stabilizing in-group cooperation over time. ${ }^{20}$

In order to see in more detail how participation depends on other-regardingness, Figure 7 shows a scatterplot of individual participation rates within each motivational category. This shows that the relationship between the individual participation rate (i.e., the fraction of the 40 periods that a subject chose to participate) and other-regardingness (measured by the angle of the motivational vector) is positive for most categories (by definition, there is no such relationship for the Individualistic category where every subject has an angle equal to zero). A regression of the participation rate on the degree of altruism produces a positive coefficient for each category, even though statistical significance is only achieved when considering the

\footnotetext{
${ }^{20}$ In fact, the slope of the time trend for strong altruists is significantly larger than that for any other type except weak altruists.
} 
full sample (see Table 2). As conjectured, for the full sample individual average participation is increasing in the degree of altruism of subjects. This result is corroborated by panel data regressions to be presented in sub-section 4.5.

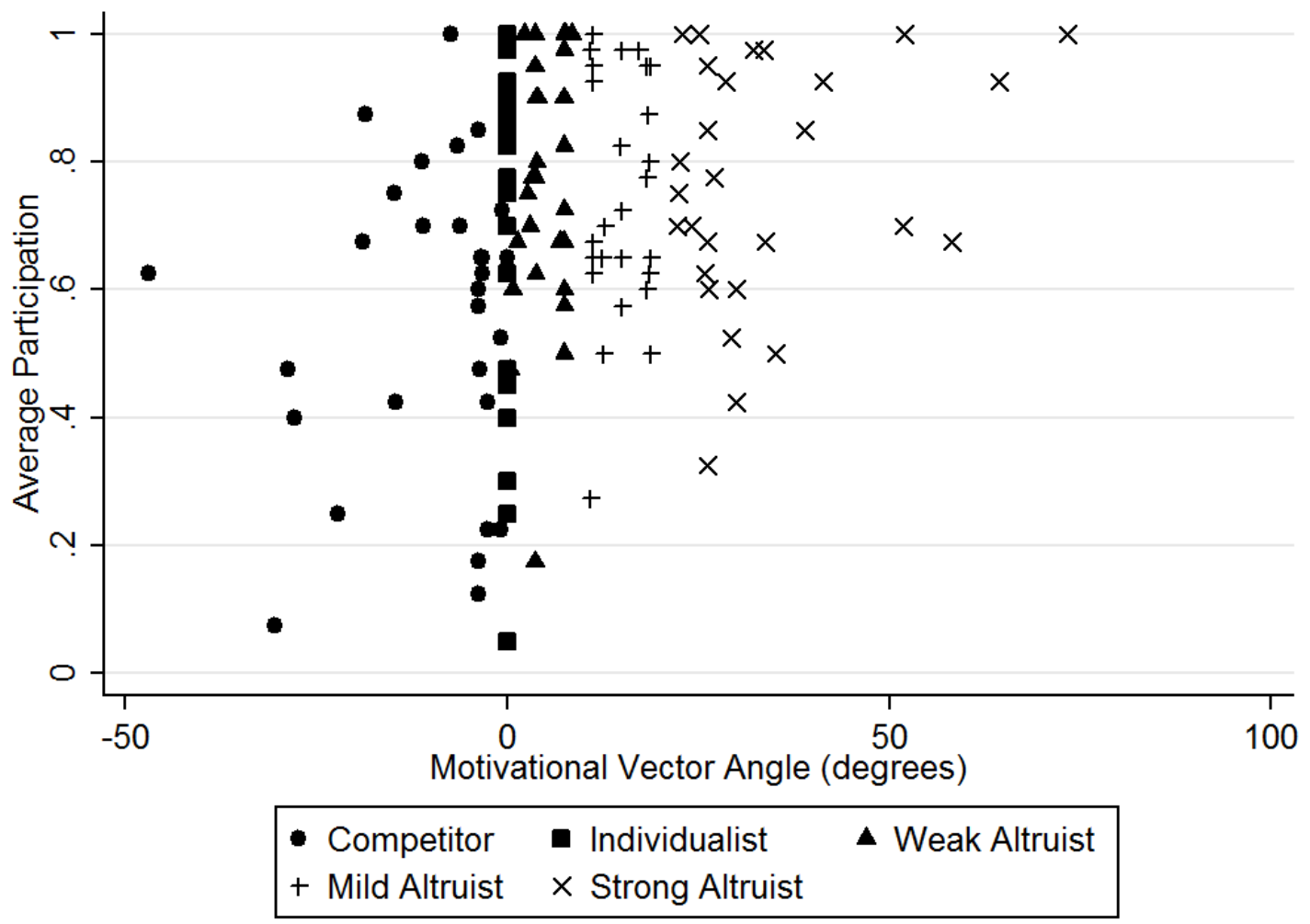

Figure 7 - Individual Participation Rates and Other-Regardingness.

Table 2 - Participation and Other-Regardingness

\begin{tabular}{l|lllll}
\hline & All Categories & Competitor & Weak A. & Mild A. & Strong A. \\
\hline $\begin{array}{l}\text { Motivational } \\
\text { Vector Angle }\end{array}$ & $0.346^{* *}$ & 0.220 & 1.840 & 0.412 & 0.383 \\
& & & & & \\
\multirow{3}{*}{ Constant } & $(3.14)$ & $(0.56)$ & $(1.27)$ & $(0.36)$ & $(1.44)$ \\
& $0.690^{* *}$ & $0.580^{* *}$ & $0.672^{* *}$ & $0.683^{* *}$ & $0.635^{* *}$ \\
& $(33.90)$ & $(9.71)$ & $(7.99)$ & $(3.91)$ & $(6.53)$ \\
\hline
\end{tabular}

Notes. The first number in each cell reports the coefficients of an OLS regression, multiplied by $10^{2}$ where the dependent variable is the fraction of times participated; $N=152$. t-statistics in parentheses. ${ }^{* *}$ indicates significance at the $1 \%$ level. Altruism is measured as the angle of the motivational vector $\left({ }^{\circ}\right)$.

All in all, our analyses show that there is a positive relationship between other-regarding preferences and contributions in the participation game. Though the effect is statistically strong at the aggregate level and appears to be present for each of the categories we 
distinguished, our results also seem to indicate that the main effect is driven by the category of competitive types, who participate much less than others. Together, this implies partial support for Hypothesis 1.

\subsection{Group Identity and Participation Behavior}

Our second and third hypotheses are concerned with the relationship between group identity and participation behavior. As formulated in Hypothesis 2a, we expect groups with stronger group attachment to exhibit higher levels of aggregate participation. At the individual level, Hypothesis $2 b$ predicts that subjects reporting a higher sense of group identity participate more often.

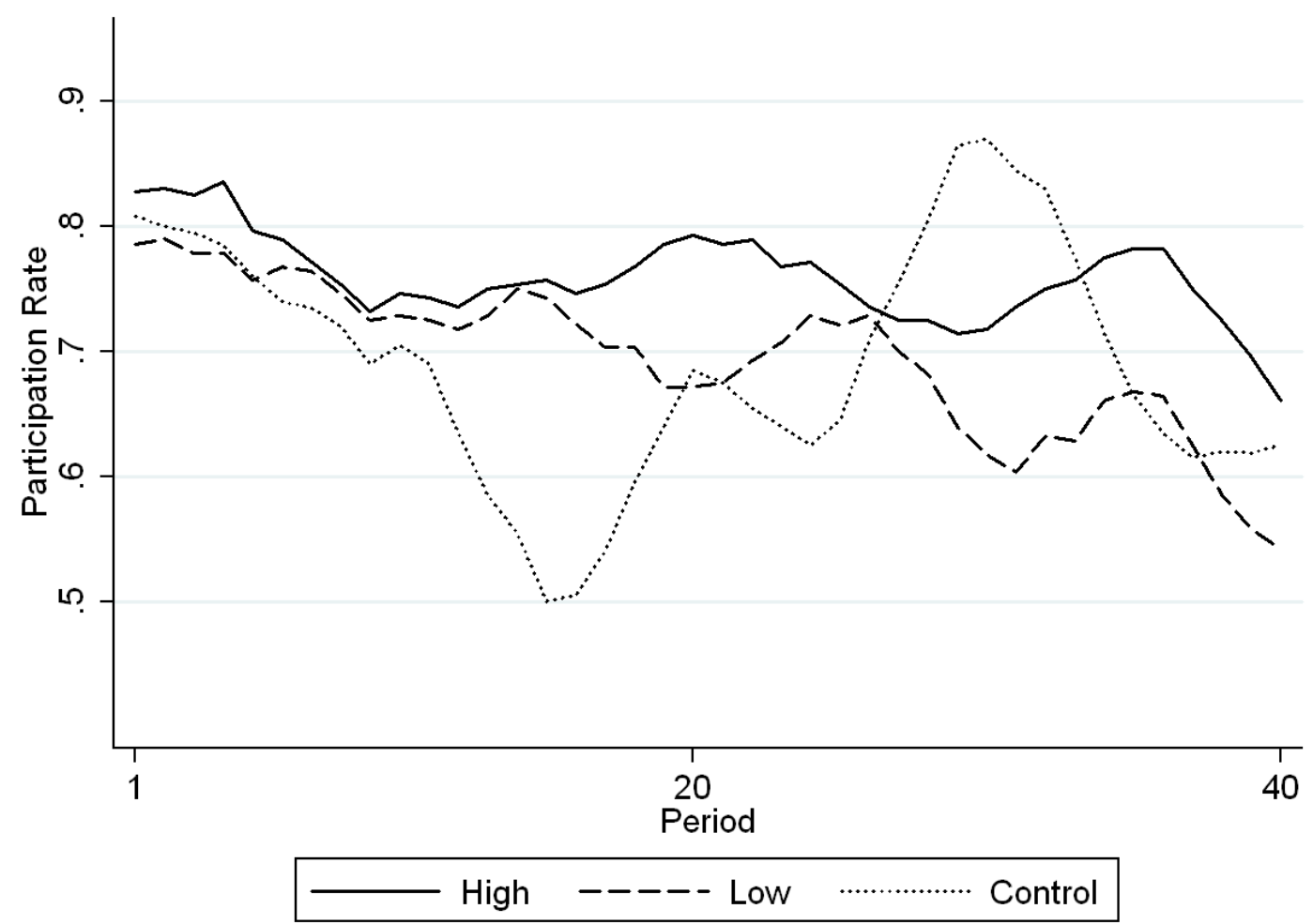

Figure 8 - Participation across Treatments.

Notes. For each treatment the corresponding line shows the five-period moving-average (two lags and two leads, where available) average participation rate.

Figure 8 shows aggregate participation levels for each of the three treatments, across the forty periods of the participation game. Aggregate participation rates vary between $46 \%$ and $90 \%$, with a higher overall participation rate in High (74.3\%) than in Low (69.3\%) and Control (69.2\%). Participation volatility is lowest in High, followed by Low and Control (standard deviations equal to $4.3 \%, 7.1 \%$ and $10.9 \%$, respectively). The participation patterns we observe are similar to previous evidence in some respects: a decrease in participation as interaction is repeated, and an abrupt decline in the last couple of periods (see Schram and Sonnemans $1996 a, b)$. In the first 10 periods participation is remarkably similar in the three treatments. As groups interact longer, we observe a departure of participation in High from the levels 
observed in Low, while Control exhibits an erratic pattern. Across all rounds, neither mean nor median participation in High is statistically different from Low and Control, however. Similarly, we observe no treatment differences in the last 20 or 10 rounds. Hence, we cannot reject a null hypothesis of no differences in favor of Hypothesis 2 a.

At the individual level, we first compare average participation across all treatments. Splitting the sample in terciles according to average allocation decision in the two dictator allocation tasks, we find that the first tercile (those with the lowest in-group bias) participates less often $(69.6 \%)$ than the second (73\%) and third (72.8\%). The difference is not statistically significant, however. At this level of aggregation, we find no support for Hypothesis $2 \mathrm{~b}$. Considering each treatment separately adds little. The only marginally significant effect is that in the control treatment, the third tercile participates more than the first ( $M W, p=0.08)$. Below, we will see that more support for the alternative hypothesis $2 \mathrm{~b}$ is obtained when using a multivariate analysis of individual behavior.

The evidence we have provided so far has basically been founded on partial analysis with little room for interaction between the relevant variables. A more detailed analysis is carried out in the next section, where we present results from a series of multivariate regression models, which allow us to provide more definite tests of these hypotheses.

\subsection{Multivariate Analysis}

For the multivariate analysis of the participation decision we use regression equations. These take the panel structure of our data into account and correct for individual heterogeneity in the participation game. We employ a logit specification in order to better accommodate those individuals with relatively extreme degrees of altruism and group identification.

Two points related to our empirical strategy are in order. First, since we observe decreasing participation rates across repetitions, with a steep decrease in the last few periods, we estimate models that include trend and squared trend terms. Second, we employ the average of the two allocation decisions as a measure for a subject's in-group bias. ${ }^{21}$ Table 3 provides the results of a logit regression explaining the decision to participate. One results is that the trend coefficient is negative and significant. We accept this result as given, but will elaborate on three other results, that provide support for each of our hypotheses.

First note that the level of altruism as measured by the angle of the motivational vector significantly and positively affects the likelihood to participate. The 'average individual' in our sample is predicted to participate approximately $80 \%$ of the times by the model. ${ }^{22} \mathrm{~A}$ marginal increase in altruism leads to an increase in the probability of participating equal to $0.36 \%$ points, an effect that is statistically significant (Wald, $p<0.01$ ). This means, for example, that an individual moving from the category Weakly Altruistic to Mildly Altruistic (a difference of approximately $10^{\circ}$ ) increases the probability of participation by approximately 3.6 percentage

\footnotetext{
${ }^{21}$ Ideally, one would prefer a continuous indicator of group identity that may have varied from one period to the next. For practical reasons, we only measure in-group bias at the beginning and ending of the participation game. The average of the two measurements provides a balanced choice. Recall that there is a great degree of consistency between the first and the second allocation decision.

${ }^{22}$ The average individual is defined as having the sample average value for each independent variable.
} 
points. The difference between the two widest vectors is $142.18^{\circ}$, which implies a predicted difference of 49.8 percentage points in participation probabilities. The significant effect of altruism on participation provides further support for Hypothesis 1. This effect is also observed when considering the High and Low treatments separately. ${ }^{23}$

Table 3 - Panel Regression Models.

\begin{tabular}{|c|c|c|}
\hline & coefficient & Marginal effect \\
\hline Motivational Vector Angle & $\begin{array}{c}0.022^{* * *} \\
(2.74)\end{array}$ & $\begin{array}{c}0.004 * * * \\
(2.69)\end{array}$ \\
\hline In-group bias & $\begin{array}{c}0.005^{*} \\
(1.72)\end{array}$ & $\begin{array}{c}0.001 * \\
(1.71)\end{array}$ \\
\hline High & $\begin{array}{c}1.096 * * \\
(2.07)\end{array}$ & $\begin{array}{c}0.162 * * \\
(2.23)\end{array}$ \\
\hline Low & $\begin{array}{l}0.397 \\
(0.89)\end{array}$ & $\begin{array}{l}0.062 \\
(0.92)\end{array}$ \\
\hline Trend & $\begin{array}{c}-0.032 * * * \\
(2.66)\end{array}$ & $\begin{array}{c}-0.005^{* * *} \\
(2.61)\end{array}$ \\
\hline Trend $^{2}$ & $\begin{array}{l}0.000 \\
(1.19)\end{array}$ & $\begin{array}{l}0.000 \\
(1.19)\end{array}$ \\
\hline In-group bias*High & $\begin{array}{c}-0.007^{*} \\
(1.72)\end{array}$ & $\begin{array}{c}-0.001^{*} \\
(1.72)\end{array}$ \\
\hline In-group bias*Low & $\begin{array}{r}-0.005 \\
(1.31)\end{array}$ & $\begin{array}{r}-0.001 \\
(1.31)\end{array}$ \\
\hline Constant & $\begin{array}{c}1.083^{* * *} \\
(2.99)\end{array}$ & --- \\
\hline
\end{tabular}

Notes. Cells present the logit estimation (with random effects at the individual level) coefficients (column 2) and marginal effects (column 3); $N=152$. High and Low are dummy variables representing these treatments. In-group bias is measured as the average of the two dictator allocation decisions. Absolute $z$-scores in parentheses. ${ }^{*}(* *, * *)$ indicates significance at the $10 \%(5 \%, 1 \%)$ level. Marginal effects for the treatment and interacted variables are calculated by restricting the estimation sample accordingly.

Second, in support of Hypothesis 2a we observe a positive aggregate effect of group identity on participation, compared to the control treatment that is significant at the 5\%-level. This follows from the coefficient estimate for the dummy variable High. Hence, being in an electorate with high group identity raises everyone's probability of participating in group action, independent of the own level of identification with the group.

Third, the coefficients for the in-group bias are supportive of Hypothesis $2 \mathrm{~b}$ (an individual effect) for the control treatment. The effect is significant at the $10 \%$-level. ${ }^{24}$ The effect is not

\footnotetext{
${ }^{23}$ The effect is also positive for the control treatment, but not statistically significantly different than zero at conventional levels.

${ }^{24}$ If we use the alternative measure of group identity (based on the responses in the questionnaire ), this effect is significant at the $5 \%$-level.
} 
significant in High or in Low, however. A similar regression for decisions in High gives a coefficient for in-group bias that is equal to -0.002 , ( $z=-0.64)$ with a marginal effect -0.0002 ( $z=-$ $0.84)$. For Low, the coefficient is $<0.0001(z=0.06)$ with marginal effect $<0.0001(z=0.06)$. We conclude that there is only a relationship between individual in-group bias and participation in groups where we have not induced group identity in any way. Indeed, in the control treatment, the coefficient for in-group bias is $0.0053(z=1.83 *)$ with a marginal effect of 0.0009 $(z=1.81)$. We will return to this point in the concluding discussion.

Finally, we consider the participation levels implied by the levels of altruism and in-group bias in our sample, i.e., we derive the models' in-sample predictions. The results of this exercise are reported in Figure 9 and show that our data describe a clear relationship between otherregarding concerns and participation. The models' predictions based on in-group bias also show a positive, albeit less clear, relationship with participation.
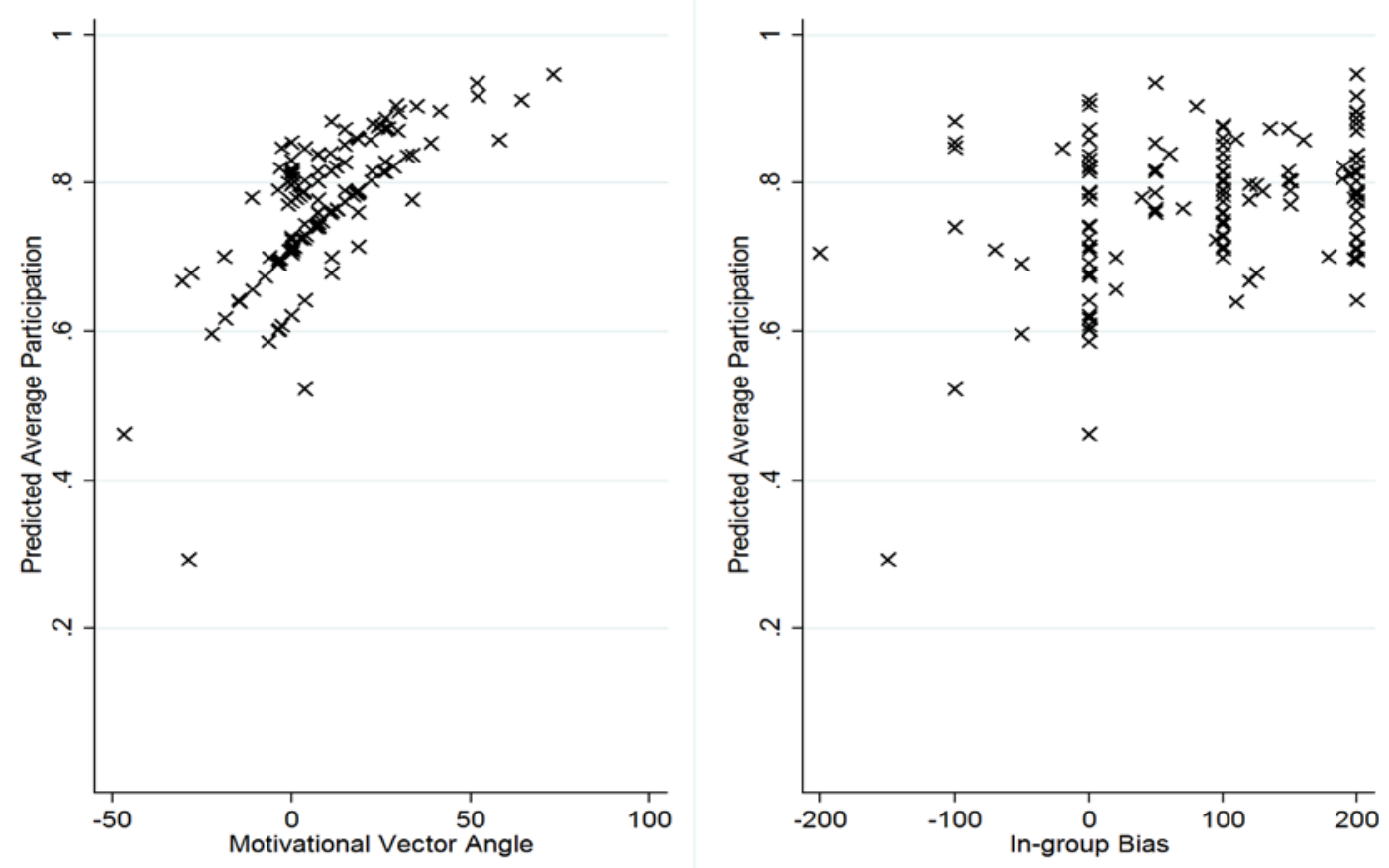

Figure 9 - In-Sample Model Predictions.

Notes. Each data point represents a model prediction of individual participation for an individual for whom all variables take average sample values except for the variable in the horizontal axis (subjects ordered in ascending of the relevant variable).

\section{Conclusion}

In his appraisal of the rational choice literature on election participation, Feddersen (2004) argues that "while a canonical model does not yet exist, the literature appears to be converging toward a 'group-based' model of turnout, in which group members participate in elections either because they are directly coordinated and rewarded by leaders as in 'mobilization' models or because they believe themselves to be ethically obliged to act in a 
manner that is consistent with the group's interest as in 'ethical agent' models." This paper is an attempt to provide further evidence to the large stream of literature that tries to evaluate political participation in light of other-regarding concerns and group-directed duties. In particular, we have used an experimental framework to address the influence of altruistic motivations and group identification on political participation decisions.

The empirical literature on the impact of group membership on participation has shown that higher social connectedness leads to higher participation levels. However, the mechanism at work is difficult to identify in the field, in the sense that it is impossible to disentangle the impact of group-level mobilization processes from the impact of group identity concerns. Our laboratory control has allowed us to isolate the latter mechanism.

We study political participation as a competition between groups, where victory depends on the sum of the individual efforts by the individuals in a group. Our experimental design allows us to measure the altruistic concerns of subjects and implement environments with different levels of group identity.

Our main conclusions are that individual participation is increasing in altruistic concerns and group attachment, as conjectured. We also found support for an impact of group identity on aggregate participation levels (but only in a multivariate analysis that corrects for the influence of confounding factors). This latter result implies that the higher participation levels observed in field studies for environments where group identification is high (e.g., contexts with pronounced ethnic divisions and high political participation) might be due to this heightened sense of group identification. Whether group mobilization adds something to this effect, is a question for further research.

Finally, there is only a correlation between individual-level sense of in-group bias and participation in our control treatment, i.e., when we did not induce any group identity. In this case, people with a large bias towards the own group tend to participate more in political action. When we induce a high sense of group identity vis-à-vis the other group, individual differences still exist (at an overall higher level) but no longer matter for the participation decision. Similarly, when our procedures induce group identity towards both the own and the other group, differences still exist (at a lower level) but do not matter for participation. In other words, individual differences within a group matter only when people experience moderate differences between the groups.

All in all, we conclude that more altruistic individuals participate more. Moreover, a common sense of identification with the group yields higher aggregate levels of political participation. As described in the previous paragraph, the effect of group identity is more complex at the individual level and depends on experienced differences between groups. Each of these results may serve as input in a canonical model as envisaged by Feddersen (2004).

\section{References}

$\mathrm{Ai}, \mathrm{C}$. and E. Norton (2003). "Interaction terms in logit and probit models." Economics Letters 80: 123--129. 
Aldrich, J. (1997). "When is it Rational to Vote?" in Perspectives on Public Choice: A Handbook, Dennis Mueller (ed.), Cambridge University Press, New York, 373--90.

Ben-Ner, A., McCall, B., Stephane, M. and H. Wang (2009). "Identity and in-group/out-group differentiation in work and giving behaviors: Experimental evidence." Journal of Economic Behavior \& Organization 72: 153--170.

Bornstein, G. (1992). "The Free-Rider Problem in Intergroup Conflicts Over Step-Level and Continuous Public Goods." Journal of Personality and Social Psychology 62 (April): 597-606.

Bornstein, G., Rapoport, A., Kerpel, L. and T. Katz (1989). "Within- and Between-Group Communication in Intergroup Competition for Public Goods." Journal of Experimental Social Psychology 25: 422-436.

Brewer, M. (2007). "The Social Psychology on Intergroup Relations: Social Categorization, Ingroup Bias, and Outgroup Prejudice." in Social Psychology: Handbook of Basic Principles, Kruglanski, A. and E. Higgins (eds.), The Guilford Press, New York.

Caprara, G., Schwart, S., Capanna, C., Vecchione, M. and C. Barbarenelli (2006). "Personality and Politics: Values, Traits, and Political Choice." Political Psychology, 27 (1): 1-28.

Charness, G., Rigotti, L. and A. Rustichini (2207). "Individual Behavior and Group Membership." American Economic Review, 97 (4): 1340-1352.

Chen, Y. and S. Li (2009). "Group Identity and Social Preferences." American Economic Review, 99 (1): 431--457.

Dawes, R. M. 1980. "Social dilemmas." Annual Review of Psychology 31: 169-93.

Dawes, C., Loewen, P. J. Fowler (2011). "Social Preferences and Political Participation." The Journal of Politics 73 (3): 845--856.

Diehl, M. (1990). "The minimal group paradigm: Theoretical explanations and empirical findings." European Review of Social Psychology 1 (1): 263-292.

Eckel, C. and P. Grossman (2005). "Managing diversity by creating team identity." Journal of Economic Behavior \& Organization 58: 371-392.

Edlin, A., Gelman, A. and Kaplan, N. (2007). "Voting as a Rational Choice: Why and How People Vote to Improve the Well-Being of Others." Rationality and Society 19 (3): 293 - 314.

Evren, O. (2010). "Altruism and Voting: A Large-Turnout Result That Does not Rely on Civic Duty or Cooperative Behavior." Working Paper.

Feddersen, T. (2004). "Rational Choice Theory and the Paradox of Not Voting." The Journal of Economic Perspectives 18 (1): 99-112.

Feddersen, T., Gailmard, S. and A. Sandroni (2009). "Moral bias in large elections: Theory and experimental evidence." American Political Science Review 103: 175-192. 
Fischbacher, U. (2007) "z-Tree: Zurich toolbox for ready-made economic experiments." Experimental Economics 10 (2): 171-178.

Fowler, J. (2006). "Altruism and Turnout." The Journal of Politics 68 (3): 674-83.

Fowler, J. and C. Kam (2007). "Beyond the Self: Social Identity, Altruism, and Political Participation." The Journal of Politics 69 (3): 813--827.

Goeree, J. K., \& Holt, C. A. (2005). An explanation of anomalous behavior in models of political participation. American Political Science Review 99(2): 201-213.

Goren, H. and G. Bornstein (2000). "The Effects of Intragroup Communication on Intergroup Cooperation in the Repeated Intergroup Prisoner's Dilemma (IPD) Game." Journal of Conflict Resolution 44 (5): 700-719.

Hofmann, K. (1991). Aus Gesprächen mit Thomas Bernhard, DTV Deutscher Taschenbuch.

Hogg, A. and D. Abrams (1998). Social Identifications: A Social Psychology of Intergroup Relations and Group Processes, Routledge, London.

Holt, C. A., \& Laury, S. K. (2002). Risk aversion and incentive effects. The American economic review, 92(5), 1644-1655. Jankowski, R. (2002). "Buying a Lottery Ticket to Help the Poor: Altruism, Civic Duty, and Self-interest in the Decision to Vote." Rationality and Society 14: 5577.

Jankowski, R. (2007). "Altruism and the Decision to Vote: Explaining and Testing High Voter Turnout." Rationality and Society 19: 5-34.

John, O., Naumann, L., and C. Soto (2008). "Paradigm Shift to the Integrative Big-Five Trait Taxonomy: History, Measurement, and Conceptual Issues." In O. P. John, R. W. Robins, \& L. A. Pervin (Eds.), Handbook of personality: Theory and research (pp. 114-158). New York, NY: Guilford Press.

Kenny, C. (1992). "Political Participation and Effects from the Social Environment." American Journal of Political Science 36 (1): 259-267.

Knack, S. (1992). "Social Altruism and Voter Turnout: Evidence from the 1991 NES Pilot Study." 1991 NES Pilot Study Reports.

Leighley, J. (2001). Strength in numbers?: The political mobilization of racial and ethnic minorities. Princeton University Press, Princeton, New Jersey.

Leighley, J. and A. Vedlitz (1999). "Race, Ethnicity, and Political Participation: Competing Models and Contrasting Explanations." The Journal of Politics 61(4): 1092-1114.

Levine, D. and T. Palfrey (2007). "The Paradox of Voter Participation? A Laboratory Study." American Political Science Review 101(1): 143-158. 
Liebrand, W. (1984). "The effect of social motives, communication and group size on behavior in an n-person multi stage mixed motive game." European Journal of Social Psychology 14: 239-264.

Lijphart, A. (1997). “Unequal Participation: Democracy's Unresolved Dilemma." American Political Science Review 91 (March): 1-14.

McKelvey, R. D. and T. R. Palfrey (1995):. "Quantal response equilibria for normal form games." Games and economic behavior 10 (1): 6-38.

Mutz, D. (2002). "The Consequences of Cross-Cutting Networks for Political Participation." American Journal of Political Science 46 (October): 838--55.

Offerman, T., Sonnemans, J. and A. Schram (1996). "Value orientations, expectations and voluntary contributions in public goods." Economic Journal 106: 817--845.

Palfrey, T. (2009). "Laboratory Experiments in Political Economy." Annual Review of Political Science 12: 379-388.

Palfrey, T., and H. Rosenthal (1983). "A Strategic Calculus of Voting." Public Choice 41 (1): 7-53.

Pollock, Ph. H. (1982). “Organizations as Agents of Mobilization: How Does Group Activity Affect Political Participation?” American Journal of Political Science 26(3): 485-503.

Schram A., and J. Sonnemans (1996a). "Voter Turnout and the Role of Groups: Participation Game Experiments." International Journal of Game Theory 25: 385-406.

Schram, A. and J. Sonnemans. (1996b). "Why People Vote: Experimental Evidence." Journal of Economic Psychology 17 (4): 417--442.

Tajfel, H. (1982). "Social Psychology of Intergroup Relations." Annual Review of Psychology 33: 1-39.

van Dijk, F., Sonnemans, J. and F. van Winden (2002). "Social Ties in a Public Good Experiment." Journal of Public Economics 85 (2): 275-299.

Verba, S. and N. Nie (1972). Participation in America: Political Democracy and Social Equality. New York: Harper and Row. 


\section{Appendix}

\section{A. Equilibria of the Participation Game}

In this appendix we formally derive equilibria of the participation game, which allows us to obtain comparative static results that inform the hypotheses we want to test. Define the set of players as $I=[1, \ldots, M, M+1, \ldots, M+N]$, where $M$ and $N$ are the number of players in groups 1 and 2, respectively. We denote the in-group and the out-group by $G_{i}$ and $G_{-i}$, respectively. We consider the case where $M=N$ and both are odd. The action space of a player has two elements: participation and non-participation. A (mixed) strategy is simply a probability of participation, which is denoted by $p$.

We posit individual preferences that accommodate general altruism towards others as well as discrimination between in-group and out-group members:

$$
U_{i}=U_{i}\left(u_{i}\left(x_{i}\right) ; U_{j}, j \in\left\{G_{i} \backslash i\right\} ; U_{h}, h \in G_{-i} ; \alpha_{i}, \beta_{i}, \gamma_{i}\right)
$$

In [1A], $U_{i}$ denotes i's utility, $x_{i}$ gives her monetary earnings and $u_{i}\left(x_{i}\right)$ describes her utility of wealth. $\alpha_{i}$ is a parameter describing the weight $i$ attributes to others' utility, relative to her own, $\beta_{i}$ is the weight she attributes to the utility of other members in her own group, and $\gamma_{i}$ is the weight she attributes to the utility of members in the other group.

To derive comparative statics for the participation game, we make the following three assumptions:

1. If members of the own group receive higher utility from an outcome than members of the other group do, then more in-group bias leads to higher utility:

$$
U_{j, j \in\left\{G_{i} \backslash i\right\}}>U_{h, h \in G_{-i}} \Rightarrow \frac{\partial U_{i}}{\partial \beta_{i}}>0
$$

2. If members of the own group receive lower utility from an outcome than members of the other group, then more in-group bias leads to lower utility:

$$
U_{j, j \in\left\{G_{i} \backslash i\right\}}<U_{h, h \in G_{-i}} \Rightarrow \frac{\partial U_{i}}{\partial \beta_{i}}<0
$$

3. The utility derived from winning the participation game (and, as a consequence, $j \in\left\{G_{i} \backslash i\right\}$ also winning and $h \in\left\{G_{-i}\right\}$ losing the participation game) is larger than the utility derived from losing the participation game (and, as a consequence, $j \in\left\{G_{i} \backslash i\right\}$ also losing and $h \in\left\{G_{-i}\right\}$ winning the participation game):

$$
\begin{array}{r}
U^{w} \equiv U_{i}\left(x_{i}=B^{w}, x_{j, j \in\left\{G_{i} \backslash i\right\}}=B^{w}, x_{h, h \in G_{-i}}=B^{l}\right)> \\
U^{l} \equiv U_{i}\left(x_{i}=B^{l}, x_{j, j \in\left\{G_{i} \backslash i\right\}}=B^{l}, x_{h, h \in G_{-i}}=B^{w}\right)
\end{array}
$$


where $U_{i}^{w}\left(U_{i}^{l}\right)$ is the utility in case of victory (defeat). Note that 3 . implies an intuitive restriction on the parameters $\alpha_{i}$ and $\beta_{i}$, i.e., they are such that any individual prefers the own team winning the participation game to the other team winning.

Equations $[2 \mathrm{~A}]-[4 \mathrm{~A}]$ yield:

$$
\frac{\partial U^{w}}{\partial \beta}>0, \frac{\partial U^{l}}{\partial \beta}<0 \Rightarrow \frac{\partial\left(U^{w}-U^{l}\right)}{\partial \beta}>0
$$

In words, [5A] states that an increase in an individual's in-group bias will lead to a higher marginal benefit of her group winning the participation game.

Next, we need to determine how this increased marginal benefit affects the choice to participate. Ceteris paribus, this will yield a higher participation probability, simply because the benefits increase while the costs remain unchanged. This is not necessarily true in an equilibrium analysis, however, because other voters may respond to variations in an individual's incentives. We therefore proceed with equilibrium analysis. We assume complete information throughout: in addition to the rules of the game, monetary payoffs and group size, we assume that players know the utility functions of all other players. This simplification does not hinder the derivation of broad comparative statics and keeps the analysis tractable. The alternative would be to adopt incomplete information (i.e. players don't know other players' preference parameters), which would require further ad hoc assumptions on preferences and beliefs.

We use a utility function of the type defined in [1A]. These individual preferences accommodate general altruism towards others as well as discrimination between in-group and out-group members (see Section 2 of the main text for an explanation of the notation):

$$
U_{i}=u_{i}+\alpha_{i}\left(\beta_{i} \sum_{j \in\left\{G_{i} \backslash i\right\}} U_{j}+\gamma_{i} \sum_{h \in G_{-i}} U_{h}\right)
$$

The utility payoff depends on whether a player is on the winning or the losing side: define $\Gamma=$ $\{w, l\}$ as these two events. Given our preference structure, the payoffs of the game are interdependent across players. Assuming that $i$ is in the winning group, [6A] can be written as:

$$
\begin{array}{r}
U_{i}^{w}=\frac{1}{\left[1-\alpha_{i}\left(\beta_{i} \sum_{j \in\left\{G_{i} \backslash i\right\}} \alpha_{j} \beta_{j}+\gamma_{i} \sum_{h \in G_{-i}} \gamma_{h} \beta_{h}\right)\right]}\left\{B^{w}\right. \\
\left.+\alpha_{i}\left[\beta_{i}\left(\sum_{j \in\left\{G_{i} \backslash i\right\}} U_{j}\right)+\gamma_{i}\left(\sum_{h \in G_{-i}} U_{h}\right)\right]\right\}
\end{array}
$$

The utility if $i$ loses, $U_{i}^{l}$, can be obtained by simply switching $B^{w}$ and $B^{l}$ in [7A]. For given preferences and for each case (winning or losing), this yields a system of $M+N$ equations (the individual utilities) in $M+N$ variables (the utility payoffs): 


$$
\begin{gathered}
{[I-\Omega] u(\Gamma)=b(\Gamma)} \\
\Rightarrow u(\Gamma)=[I-\Omega]^{-1} b(\Gamma)
\end{gathered}
$$

where $I_{((M+N) \times(M+N))}$ is the identity matrix,

$$
\Omega_{((M+N) \times(M+N))}=\left[\begin{array}{ccccccc}
0 & \alpha_{1} \beta_{1} & \ldots & \alpha_{1} \beta_{1} & \alpha_{1} \gamma_{1} & \ldots & \alpha_{1} \gamma_{1} \\
\alpha_{2} \beta_{2} & \ddots & & & & & \alpha_{2} \gamma_{2} \\
\vdots & & & & & & \vdots \\
\alpha_{M} \beta_{M} & & & & & & \alpha_{M} \gamma_{M} \\
\alpha_{M+1} \gamma_{M+1} & & & & & & \alpha_{M+1} \beta_{M+1} \\
\vdots & & & & & \ddots & \vdots \\
\alpha_{M+N} \gamma_{(M+N)} & & \ldots & \alpha_{M+N} \gamma_{(M+N)} & \alpha_{M+N} \beta_{(M+N)} & \ldots & 0
\end{array}\right],
$$

$u(w)=\left(U_{1}^{w}, \ldots, U_{M}^{w}, U_{N}^{l}, \ldots, U_{M+N}^{l}\right)^{\prime}$, and $b(w)=\left(B^{w}, \ldots, B^{w}, B^{l}, \ldots, B^{l}\right)^{\prime}$ (with the case of $\Gamma=l$ defined accordingly). The solution to [8A] allows us to calculate the utility of a winning and losing player for any combination of $B^{w}, B^{l}, C$ and other-regarding and in-group bias parameters $(\Omega)$.

Following Palfrey and Rosenthal (1983), it can be shown that for the case with equal group sizes there exists a unique Nash Equilibrium in pure strategies with full participation (for $c<\left(U^{w}-U^{l}\right) / 2$ ). In addition, a plethora of mixed-strategy Nash equilibria exist. To refine this set, and for reasons discussed in Section 2 of the main text, the analysis of participation games has often resorted to the quantal response equilibrium concept (QRE; McKelvey and Palfrey 1995).

Adding a stochastic component to decision rules [2] and [3] in the main text, $\left(\mu \varepsilon_{i j}, j=\right.$ $\{P, N P\}$, respectively) implies that a player prefers participation to non-participation if:

$$
[\operatorname{Pr}[m=n]+\operatorname{Pr}[m=n-1]] \frac{\left(U_{i}^{w}-U_{i}^{l}\right)}{2}-c>\mu\left(\varepsilon_{i P}-\varepsilon_{i N P}\right)
$$

where $\mu$ is a parameter that governs the extent of bounded rationality (noise) in players' decisions, and the $\varepsilon_{i j}$ represent i.i.d. realizations of a random variable.

Following much of the literature, we assume that the difference of the errors in $[9 \mathrm{~A}]$ follows a logistic distribution. This implies the following equilibrium condition for each player (see Goeree and Holt 2005 for details):

$$
p_{i}=\frac{1}{1+\exp \left[\frac{c-\left[(\operatorname{Pr}[m=n]+\operatorname{Pr}[m=n-1]) \frac{\left(U_{i}^{w}-U_{i}^{l}\right)}{2}\right]}{\mu}\right]}, i=1, \ldots, 10
$$

The $\mu$ parameter is typically estimated from experimental data. Goeree and Holt (2005) show that a value of $\mu=0.8$ accommodates the data of Schram and Sonnemans (1996a), in which participation fluctuates in the $30-50 \%$ range. Since we observe higher participation levels, our data would possibly imply a slightly higher value of $\mu$. For our purposes the precise value of this parameter is not particularly relevant as only point predictions, and not comparative 
statics, will depend on it. For this reason, we use $\mu=0.8$, for the numerical QRE results that we present.

\section{In-group Bias and Aggregate Participation}

To start, we consider totally quasi-symmetric equilibria (Palfrey and Rosental 1983) where all voters in group 1 vote with the same probability $p_{G 1}$ and all voters in group 2 vote with the same probability $p_{G 2}$. For participation games where both groups have equal size the probability terms are then defined as (for a player in group 1):

$$
\begin{gathered}
\operatorname{Pr}[m=n]=\sum_{k=0}^{M-1}\left(\begin{array}{c}
M-1 \\
k
\end{array}\right)\left(\begin{array}{l}
N \\
k
\end{array}\right)\left(p_{G 1}\right)^{k}\left(1-p_{G 1}\right)^{M-1-k}\left(p_{G 2}\right)^{k}\left(1-p_{G 2}\right)^{N-k} \\
\operatorname{Pr}[m=n-1]=\sum_{k=0}^{M-1}\left(\begin{array}{c}
M-1 \\
k
\end{array}\right)\left(\begin{array}{c}
N \\
k+1
\end{array}\right)\left(p_{G 1}\right)^{k}\left(1-p_{G 1}\right)^{M-1-k}\left(p_{G 2}\right)^{k+1}\left(1-p_{G 2}\right)^{N-k-1}
\end{gathered}
$$

The assumption that in equilibrium every player in the same group participates with the same probability can be intuitively justified by the assumption that players are homogenous in their other-regarding preferences. For our analysis, we further assume here that players in both groups have the same parameters (and therefore, $p_{G 1}=p_{G 2}=p$ ), which means that we will investigate how equilibria change when we vary the in-group bias parameters for all players. Our strategy is to numerically determine the equilibrium $p$ for distinct parameters and to deriver comparative static predictions from comparing these equilibria.

We first determine the effect of in-group bias for this homogenous case. With respect to the preferences posited in [6A] (with $\alpha_{i}=\alpha, \beta_{i}=\beta_{i} \gamma_{i}=\gamma, \forall_{\mathrm{i}}$ ) we implement five parameterizations that use $\alpha=0.12$ (the average slope of the motivational vector in our data) but have different in-group bias ratios $\beta / \gamma=\{0,1 / 3,1,3, \infty\}$. For each parameter configuration, we solve [8A] and substitute the result and the above probabilities in $[10 \mathrm{~A}]$ and solve for $p$. This yields the QRE $p=\{0.26,0.28,0.32,0.48,0.58\}$, respectively These are also the predicted levels of aggregate participation. We conclude that for the homogenous case, and the moderate level of altruistic concerns found in our data $(\alpha=0.12)$, equilibrium (aggregate) participation is increasing in in-group bias.

\section{Altruism, In-group Bias and Individual Participation}

Next, we drop the assumed homogeneity and allow for different mixed strategies for each player. This enables an investigation of the comparative statics at the individual level. The probability terms become, for each player $i$ :

$$
\begin{gathered}
\operatorname{Pr}[m=n]=\sum_{j=1}^{126} \prod_{h \neq i} p_{h}^{A_{j k}}\left(1-p_{h}\right)^{\left(1-A_{j k}\right)}, k=\left\{\begin{array}{l}
h, \text { if } h<i \\
h-1, \text { else }
\end{array}\right. \\
\operatorname{Pr}[m=n-1]=\sum_{j=1}^{126} \prod_{h \neq i} p_{h}^{B_{j k}}\left(1-p_{h}\right)^{\left(1-B_{j k}\right)}, k=\left\{\begin{array}{l}
h, \text { if } h<i \\
h-1, \text { else }
\end{array}\right.
\end{gathered}
$$


where the $A_{j k}$ correspond to the elements of a matrix, $A_{(126 \times 10)}$, whose rows contain combinations of binary elements corresponding to cases where $m=n$ (a total of 126 cases). For example, for player $i=1$ :

$$
A_{(126 \times 10)}=\left[\begin{array}{cccccccccc}
-1 & 1 & 1 & 1 & 1 & 1 & 1 & 1 & 1 & 0 \\
-1 & 1 & 1 & 1 & 1 & 1 & 1 & 1 & 0 & 1
\end{array}\right]
$$

We use -1 for the (unused) element of player $i$. As an example, consider the first row. This indicates the case where all of player $i(=1)$ 's co-members vote, and four of the other group's members do so, which yields a 4-4 tie that makes her pivotal. There are five such configurations that yield a 4-4 tie (any of the five members of the other group can abstain). For the case of a 3-3 tie, there are 20 configurations (five for each of the four possible abstainers in the own group). In aggregate, this yields 126 situations where player $i$ faces a tie. The matrix $B$ is defined in an analogous way for the cases where she is pivotal because she can turn a loss into a tie, i.e., $m=n-1$.

For diverse parameter sets, we again solve [8A] and substitute the results with the probabilities of being pivotal in [9A]. This allows us to numerically compute the vector of QRE probabilities, $p_{i}$. We do so for parameter configurations in which we induce heterogeneity either in $\alpha_{i}$ (individual other-regarding concerns) or in $\beta_{i} / \gamma_{i}$ (individual in-group bias). Tables A.1 and A. 2 present parameterizations for these two cases, respectively.

We induce other-regarding heterogeneity by allowing each player in a group to have a different $\alpha_{i}$, while keeping groups symmetric for parsimony reasons. One player, call it player 1 , has a baseline value of $\alpha_{1}=\alpha^{*}$, which increases with an increment of 0.1 for the subsequent players, such that player 4 has $\alpha_{4}=\alpha^{*}+0.3$, for example. We compute equilibria for seven different values of $\alpha^{*}$, which were chosen such that values within two standard deviations of the average $\alpha$ in our data are covered. For each of these baseline values of $\alpha^{*}$, we compute equilibrium probabilities for seven values of in-group bias, which is kept constant in both groups $(\overline{\beta / \gamma})$. We therefore have forty-two parameter configurations. For each configuration, the individual participation probabilities always have a monotonic relationship with respect to the incremented parameter.

The results are presented in Table A.1. For each parameterization we report whether this relationship is negative $\left({ }^{\prime}-{ }^{\prime}\right)$, positive $\left({ }^{\prime}+{ }^{\prime}\right)$ or constant $\left({ }^{\prime}=\prime\right)$. We observe that the individual probability of participation is generally increasing in other-regarding concerns for in-group bias levels of $4 / 3$ and above. If the in-group bias is smaller than 1 (i.e., I prefers the other group), more altruistic people vote less. For the average level of other-regarding concerns in our data $(\alpha=0.12)$, individual participation is increasing in other-regarding concerns for all values of ingroup favoritism. This relationship is reversed when a high level of other-regarding concerns is combined with very high values of in-group favoritism, though one may doubt the empirical relevance of this combination (it is not observed in our data). In general, the results presented in Table A.1 provide support to Hypothesis 1: individual participation is increasing in otherregarding for parameter values that are empirically relevant. 
Table A 1 - Other-regarding concerns and individual participation.

\begin{tabular}{|c|c|c|c|c|c|c|c|}
\hline$\alpha^{*}$ & $\overline{\beta / \gamma}$ & 0 & $2 / 3$ & $4 / 3$ & 2 & $8 / 3$ & $\infty$ \\
\hline-0.75 & & + & - & + & + & + & + \\
\hline-0.5 & & + & - & + & + & + & + \\
\hline-0.25 & & - & - & + & + & + & + \\
\hline 0 & & - & - & + & + & + & + \\
\hline 0.25 & & - & - & + & + & + & - \\
\hline 0.5 & & - & - & + & + & - & - \\
\hline 0.75 & & - & - & + & + & - & - \\
\hline \multicolumn{8}{|c|}{$\begin{array}{l}\text { Notes. The parameter } \alpha \text { takes a baseline value for each parameterization, } \alpha^{*} \text {, which is incremented in } \\
\text { steps of } 0.1 \text { for the players in each group in order to generate heterogeneity. The relationship } \\
\text { between individual participation probabilities and } \alpha \text { can be negative }\left({ }^{\prime}-{ }^{\prime}\right) \text {, positive }\left({ }^{\prime}+{ }^{\prime}\right) \text { or } \\
\text { constant }\left({ }^{\prime}={ }^{\prime}\right) \text {. }\end{array}$} \\
\hline
\end{tabular}

Table A.2 uses the same procedure to induce heterogeneity in the individual in-group bias parameters, i.e. each player in one of the symmetric groups has a different $\beta_{i} / \gamma_{i}$. One player, call it player 1 , has a baseline value of $\beta_{1} / \gamma_{1}=\beta^{*} / \gamma^{*}$. The $\beta(\gamma)$ increases (decreases) with an increment of 0.1 for the subsequent players, such that player 4 has $\beta_{4} / \gamma_{4}=\left(\beta^{*}+0.3\right) /\left(\gamma^{*}-\right.$ $0.3)$. We compute equilibria for six different values of $\beta^{*} / \gamma^{*}$, the ones presented in Table A.1. except 0 (such that in-group bias does not take negative values). The presented results show that individual participation is increasing in individual in-group bias for low values of otherregarding concerns. For values of $\alpha$ above 0.5 (which seem empirically irrelevant), an in-group bias above $8 / 3$ (i.e. $\beta>0.72$ ) leads to a negative relationship. The in-group bias measurement that we implemented in the experiment does not allow for a precise correspondence between the subjects' choices and the parameters of our model. However, we find it plausible that someone allocating $3 / 4$ of the endowment to the in-group member cares three times more about the in-group, and therefore has an in-group bias ratio of $\beta / \gamma=3$. Subjects allocated an average of 148.6 out of 200 tokens to the in-group member (pooling all treatments and both decisions), which leads us to believe that such a ratio is plausible. Assuming an other-regarding parameter equal to the data average, our results support Hypothesis 2.b in the sense that individual participation is increasing in in-group bias in a parameter range that is compatible with the observed data. 
Table A 2 - In-group bias and individual participation.

\begin{tabular}{|c|c|c|c|c|c|c|}
\hline $\bar{\alpha}$ & $\beta^{*} / \gamma^{*}$ & $2 / 3$ & $4 / 3$ & 2 & $8 / 3$ & $\infty$ \\
\hline-0.75 & & - & - & - & - & - \\
\hline-0.5 & & - & - & - & - & - \\
\hline-0.25 & & - & - & - & - & - \\
\hline 0 & & $=$ & $=$ & $=$ & $=$ & $=$ \\
\hline 0.25 & & + & + & + & + & + \\
\hline 0.5 & & + & + & + & - & - \\
\hline 0.75 & & + & - & - & - & - \\
\hline $\begin{array}{l}\text { Notes. The } \\
\beta^{*} / \nu^{*} \text {, whi } \\
\text { heterogene } \\
\text { can be neg }\end{array}$ & $\begin{array}{l}\text { e relat } \\
\left.{ }^{\prime}-{ }^{\prime}\right), p c\end{array}$ & $\begin{array}{l}\text { tak } \\
\text { for } \\
\text { bet } \\
\left({ }^{\prime}+{ }^{\prime}\right)\end{array}$ & $\begin{array}{l}\text { ndivi } \\
\text { tant }\end{array}$ & & $\begin{array}{l}p \\
\text { ord }\end{array}$ & $\begin{array}{l}\text { ization, } \\
\text { enerate } \\
\text { and } \beta / \gamma\end{array}$ \\
\hline
\end{tabular}

\section{B. Value Orientation Test}

The ring test of van Dijk et al. (2002) is reproduced in table B1:

Table B 1: Ring Test

\begin{tabular}{c|ccccccccc}
\hline Decision & \multicolumn{2}{|c}{ Alternative A } & \multicolumn{2}{c}{ Alternative B } & Decision & \multicolumn{2}{c}{ Alternative A } & \multicolumn{2}{c}{ Alternative B } \\
\hline & Self & Other & Self & Other & & Self & Other & Self & Other \\
1 & 0 & 500 & 304 & 397 & 17 & 0 & -500 & -304 & -397 \\
2 & 304 & 397 & 354 & 354 & 18 & -304 & -397 & -354 & -354 \\
3 & 354 & 354 & 397 & 304 & 19 & -354 & -354 & -397 & -304 \\
4 & 397 & 304 & 433 & 250 & 20 & -397 & -304 & -433 & -250 \\
5 & 433 & 250 & 462 & 191 & 21 & -433 & -250 & -462 & -191 \\
6 & 462 & 191 & 483 & 129 & 22 & -462 & -191 & -483 & -129 \\
7 & 483 & 129 & 496 & 65 & 23 & -483 & -129 & -496 & -65 \\
8 & 496 & 65 & 500 & 0 & 24 & -496 & -65 & -500 & 0 \\
9 & 500 & 0 & 496 & -65 & 25 & -500 & 0 & -496 & 65 \\
10 & 496 & -65 & 483 & -129 & 26 & -496 & 65 & -483 & 129 \\
11 & 483 & -129 & 462 & -191 & 27 & -483 & 129 & -462 & 191 \\
12 & 462 & -191 & 433 & -250 & 28 & -462 & 191 & -433 & 250 \\
13 & 433 & -250 & 397 & -304 & 29 & -433 & 250 & -397 & 304 \\
14 & 397 & -304 & 354 & -354 & 30 & -397 & 304 & -354 & 354 \\
15 & 354 & -354 & 304 & -397 & 31 & -354 & 354 & -304 & 397 \\
16 & 304 & -397 & 0 & -500 & 32 & -304 & 397 & 0 & 500 \\
\hline
\end{tabular}


Figure B1 reproduces a snapshot of the first decision in our experimental environment:

Figure B 1: Screenshot

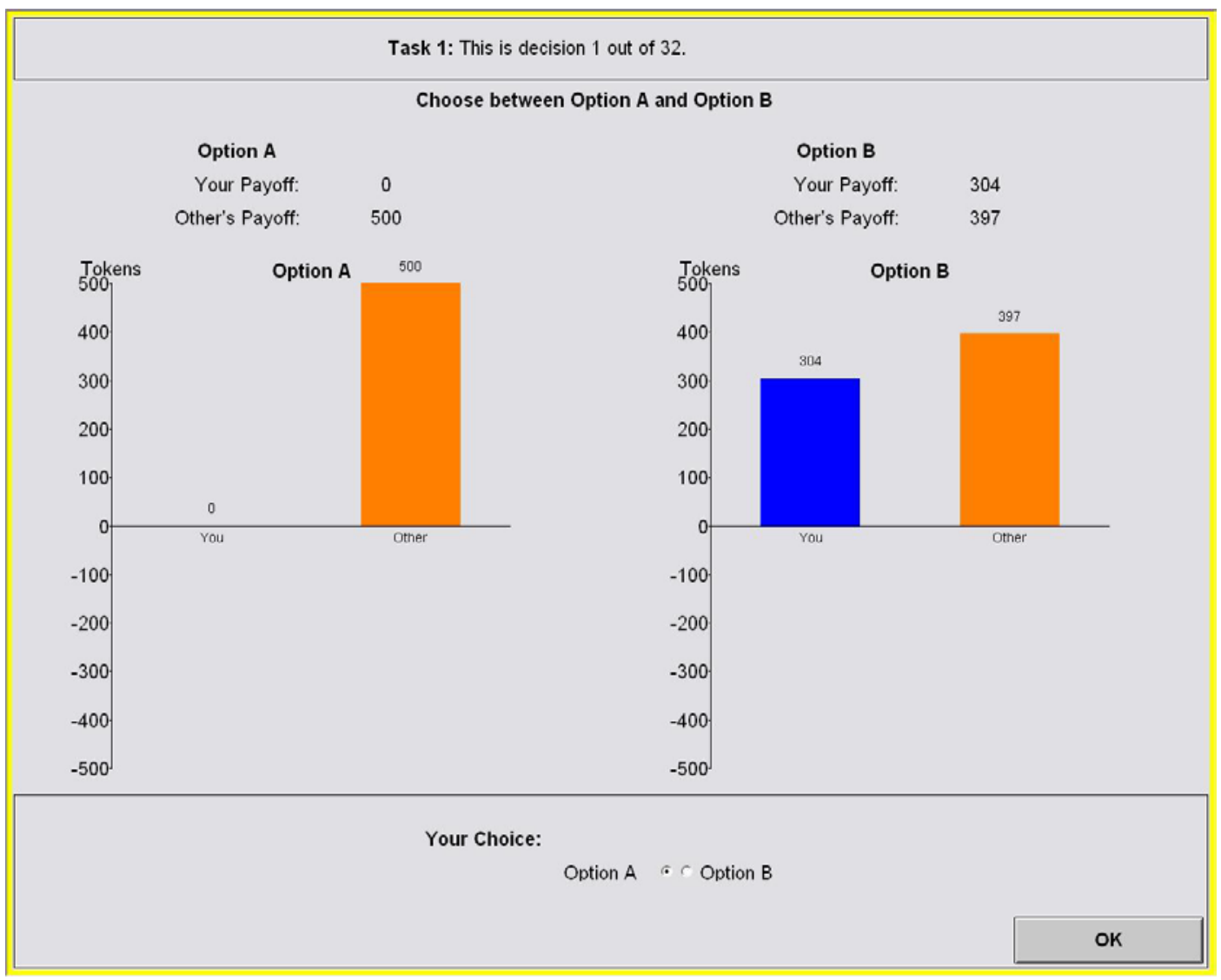

\section{Auxiliary Tables}

Table C1 presents the choices of subjects regarding the motivations of different strategies in the participation game. This information was collected in the post-experimental questionnaire. Note that the presented options correspond to a number of motivations (with a rough correspondence in our preference specification): individualistic $(\alpha=0)$, competitive $(\alpha<0)$, ingroup co-operator $(\alpha>0, \beta>\gamma)$, overall co-operator $(\alpha, \beta=\gamma)$.

Table C.1 - Reported Motivations in the Questionnaire

\begin{tabular}{l|cc}
\hline Main goal of a participant who... & $\begin{array}{c}\text {...participated most of } \\
\text { the times. }\end{array}$ & $\begin{array}{c}\text {...did not participate } \\
\text { most of the times. }\end{array}$ \\
\hline $\begin{array}{l}\text { Make as much money as possible for himself or } \\
\text { Increase the difference between his or her }\end{array}$ & $27.50 \%$ & $77.50 \%$ \\
$\begin{array}{l}\text { earnings and the earnings of other participants. } \\
\text { Help his or her group make as much money as }\end{array}$ & $1.88 \%$ & $20.00 \%$ \\
$\begin{array}{l}\text { Help both his or her group and the other group } \\
\text { make as much money as possible. }\end{array}$ & $63.75 \%$ & $1.25 \%$ \\
\hline
\end{tabular}


Table C2 presents OLS regression results on the relationship between personality traits and participation behavior, and between personality traits and other-regardingness.

Table C.2 - Participation, Personal Traits and Value Orientation

\begin{tabular}{l|cc}
\hline & $\begin{array}{c}\text { Average Participation } \\
\text { Agreeableness }\end{array}$ & $\begin{array}{c}\text { Altruism (motivational vector's } \\
\text { angle) }\end{array}$ \\
Conscientiousness & $-.0608^{*}$ & 0.080 \\
& $(-1.71)$ & $(0.03)$ \\
Extraversion & .007 & 2.167 \\
& $(0.24)$ & $(0.93)$ \\
Openness & .029 & -2.539 \\
& $(0.93)$ & $(-1.09)$ \\
Neuroticism & -.056 & 0.449 \\
& $(-1.64)$ & $(0.19)$ \\
Altruism (motivational vector's & .007 & -2.321 \\
angle) & $(0.22)$ & $(-0.90)$ \\
Constant & $.003^{* *}$ & \\
& $(3.02)$ & 16.196 \\
$R^{2}$ & $.975^{* *}$ & $(0.98)$ \\
\hline OLS regression. $N=152$. t-statistics in parentheses. * & $(4 *)$ indicates significance at the $10 \%(1 \%)$ level. \\
\hline
\end{tabular}

Table C3 presents OLS regression results on the relationship between average individual participation and a linear trend, for each motivational category.

Table C.3 - Regression of Average Participation on a Linear Trend

\begin{tabular}{l|ccccc}
\hline & Competitors & Individualists & Weak Altruists & Mild Altruists & Strong Altruists \\
\hline Constant & $0.682^{* *}$ & $0.794^{* *}$ & $0.845^{* *}$ & $0.804^{* *}$ & $0.734^{* *}$ \\
& $(34.42)$ & $(40.12)$ & $(30.58)$ & $(37.05)$ & $(23.83)$ \\
Linear Trend & $-0.601^{* *}$ & $-0.210^{*}$ & $-0.373^{* *}$ & $-0.296^{* *}$ & 0.150 \\
& $(-7.21)$ & $(-2.49)$ & $(-3.21)$ & $(-3.21)$ & $(1.15)$ \\
$R^{2}$ & 0.58 & 0.14 & 0.21 & 0.21 & 0.03 \\
& \multicolumn{7}{l}{$\begin{array}{l}\text { OLS regression, } N=152 . \text { t-statistics in parentheses. }{ }^{*}\left({ }^{* *}\right) \text { indicates significance at the } 10 \%(1 \%) \text { level. } \\
\text { Linear trend coefficients multiplied by } 10^{2} .\end{array}$} \\
\hline
\end{tabular}


Table C4 presents the distribution of subjects across motivational categories and treatments.

Table C.4 - Conditional Distribution of Subjects

\begin{tabular}{l|cccccc}
\hline & Competitors & Individualists & Weak Altruists & Mild Altruists & Strong Altruists & Total \\
\hline High & 0.06 & 0.09 & 0.07 & 0.07 & 0.08 & 0.36 \\
Low & 0.09 & 0.06 & 0.08 & 0.08 & 0.06 & 0.38 \\
Control & 0.05 & 0.09 & 0.05 & 0.03 & 0.05 & 0.27 \\
\hline
\end{tabular}

\section{Other-regarding Preferences and Group Identity}

In this appendix we examine the relationship between altruism and group identity. In other words, we are interested in whether distinct motivational types respond differently to group identity manipulations. For this purpose, Figure D.1 shows the average percentages of the endowment allocated to the in-group member - both before and after the participation game - per motivational category and treatment.

Consider first the average in-group bias across treatments. Individualistic is the category showing the highest in-group bias, with an average allocation of $79,1 \%$ of the endowments to the in-group. The group showing the lowest in-group bias is Competitors, for whom the average allocation to the in-group member is $67.4 \%$. Despite the apparent diversity in allocation behavior, the only significant difference across categories when using the average of the two decisions is between Competitors and Individualists (MW, $\mathrm{p}=0.05$ ). A Pearson's chisquare test corroborates this claim: there is no significant systematic difference over categories for the average of the two decisions, neither across all treatments, nor for any particular treatment (all $p>0.35$ ). In the allocation decision before the Participation Game the bias is stronger for Individualists than for Competitors and Mild Altruists (MW, $p=0.02$ for both comparisons; pooling over treatments). For the allocation after the Participation Game, there are no statistically different decisions across motivational types. We conclude that subjects with distinct other-regarding preferences do not exhibit strong and systematic differences in in-group bias if we pool over treatments. 

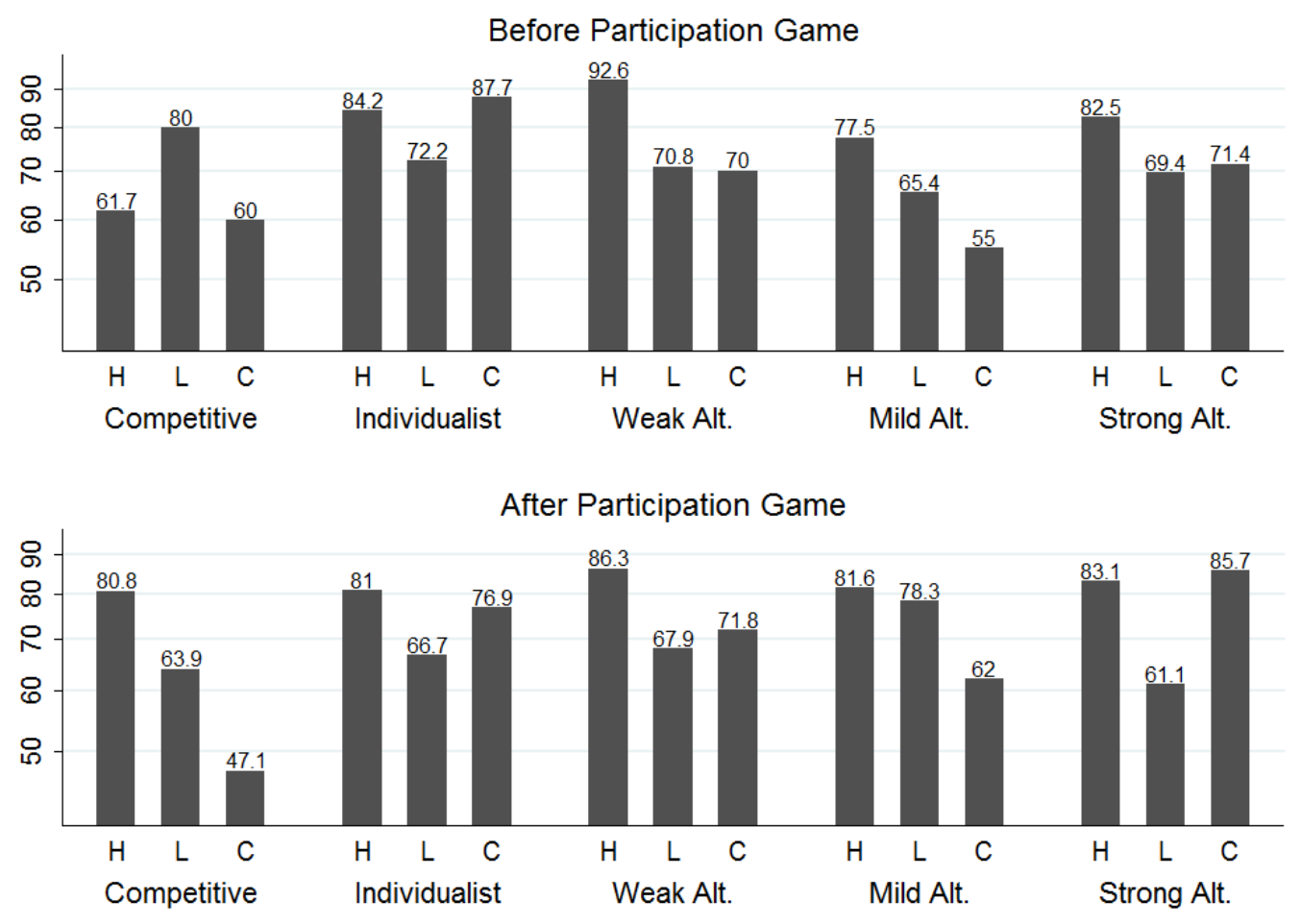

Figure D. 1 - Altruism and Group Identity

Notes: bars depict, for each motivational category, the average allocation to the member of the in-group, as measured before (upper panel) and after (lower panel) the participation game.

Some types react differently to distinct group identity manipulations, however. Considering the average of the two decisions, we find (sometimes weak) evidence of differential behavior of Weak Altruists between High and Control (MW, $\mathrm{p}=0.07$ ), Strong Altruists between High and Low (MW, $\mathrm{p}=0.04$ ), and Mild Altruists between both High and Low, and High and Control (MW, $p=0.05$ and $p=0.08$, respectively). Other comparisons do not reach statistical significance levels below 0.10. Bearing in mind that we observed in the main text (section 5.2) a difference between the average allocation in High and in the other two treatments, this evidence suggests that differences in group attachment across treatments are mostly driven by the three altruistic types. Altruistic types not only share more with an anonymous other, they also allocate a relatively higher amount to the member of their in-group when group identity is high.

Next, we consider whether our subjects' in-group bias is affected by the interaction in the participation game. Eyeballing Figure D.1 suggests similar patterns across the two decisions, with a possible exception for Competitors. The difference between the two decisions is not statistically significant for this group, nor for any other, however. ${ }^{25}$ The changes between the two measurements are symmetric. We observe some instances where subjects seem to be

\footnotetext{
${ }^{25}$ At this level, the numbers of observations are small. The conclusions do not change if we aggregate data. Pooling across treatments, there is only evidence of different behavior for Mild Altruists across the two decisions (MW, $\mathrm{p}=0.08$ ). Pooling across types, we observe no statistically significant differences for any treatment, when comparing behavior before and after the participation game.
} 
punishing their group $(21.05 \%$ of the subjects decrease their allocation to the in-group after the Participation Game), a majority of subjects exhibiting stable in-group bias (54.61\%) and some rewarding the in-group by giving more after the participation game (24.34\%).

\section{E. Experimental Instructions}

In this appendix we reproduce the experiment's instructions. Italicized text corresponds to text that was part of High and Low but not Control. Trivia questions and other non-reproduced details are available upon request.

Welcome to this experiment in decision-making. Depending on your decisions and the decisions of other subjects you may earn money. You will be paid privately at the end of the session. This is an anonymous experiment: your identity will not be revealed to other participants. The choices you make in early parts of the experiment may be used in later parts. Since this experiment involves gains and losses, it is possible (though very unlikely) that you make a negative amount in the experiment. In that case, your earnings will be deducted from the show-up fee. It is not possible that your losses exceed the show-up fee. This experiment is composed of three main tasks: Task 1, Task 2, and Task 3. You will receive instructions for a new task after the previous one has been completed. Note that a new task will only begin when every participant has finished the previous one.

Ring Test: In Task 1 you will be asked to make 32 decisions with monetary consequences. In each of the 32 situations you will have to choose between two options: Option A and Option B. For each option, two numbers will be displayed. The first is the number of tokens that you yourself will receive (positive amounts) or pay (negative amounts). The second is the number of tokens that the "Other" will receive or pay as a consequence of your decision. The "Other" is an anonymous person in this room, with whom you are randomly matched for the entire duration of Task 1 . You will also be randomly matched with a second, different anonymous participant whose choices will affect you in the same way that your choices affect the "Other". Note: this means that the person who receives or loses money due to your decisions is a different person than the one whose decisions make you earn or lose money.

Your total payoff is the result of both your decisions and the decisions made by the participant whose choices affect you. No participant will know with whom he or she has been paired. Participants will only be informed about the total amount they earned or lost at the end of the experiment.

BFI: In Task 2 you will be asked to rate a number of characteristics that may or may not apply to you. There are 44 statements in total, distributed over 4 screens. Please pick a number from 1 to 5 next to each statement to indicate the extent to which you agree or disagree with that statement. Most people take no more than 10 minutes to complete this task.

The Openness Score: The statements you rated in Task 2 constitute a self-report inventory of personality traits (characteristics). We employed one of the most used and reliable personality trait tests. One of the traits that was measured is 'Openness', whose score can range from 1 to 5 .

What is Openness?: Openness is a personality trait that involves active imagination, aesthetic sensitivity, attentiveness to inner feelings, preference for variety, and intellectual curiosity. It captures receptivity to novel experiences and ideas. It is not the cultural habits and knowledge acquired through education or breeding, nor is it related to intelligence or any other cognitive ability.

People whose Openness Score lies more to the left-hand side of the scale:

- tend to be more conventional and traditional in their opinions and behavior. 
- prefer familiar routines to new experiences.

- generally focus on a narrower range of interests.

- are practical and down-to-earth.

- are able to more easily separate ideas from feelings.

People whose Openness Score lies more to the right-hand side of the scale

- are curious, open to unknown things and variety.

- are frequently described as imaginative, artistic, unconventional and tolerant.

- are more willing to accept the validity of astrology and esoteric phenomena.

- have more easily access to thoughts and feelings simultaneously, thus experiencing things more intensely.

We have constructed a ranking of the Openness Scores of the twenty participants of this experiment. This ranking ranges from 1 to 20, with 1 being the participant with the Openness Score more to the right, and 20 the participant with the Openness Score more to the left.

We would like to ask the ten participants with rankings 1 to 10 to move to another lab. Please wait for the organizers' instructions to do so. The other ten participants can remain seated. Given your ranking, we would kindly ask you to prepare to move to the other lab/remain seated.

\section{After Moving and Sitting Down at New Computer Stations}

For the next 3 minutes, we would like the participants in each lab to pick a name to identify their lab. We provide you with three pre-defined possibilities. You can discuss this with the other participants in the same lab as you by using the chat box below.

Each participant submits his preferred choice, and the most picked choice will be the name that will identify your lab for the remainder of the experiment.

Trivia Challenge: The participants in [name of the participant's lab] and [name of the other lab] will now compete in a trivia challenge. Each participant will be asked five trivia questions. You have 30 seconds to answer each question. You cannot answer after time is up. Each correct answer corresponds to one point, an incorrect answer corresponds to zero points. In the end, the points of all participants in [name of the participant's lab] will be summed, and compared to the total number of points achieved by the participants in [name of the other lab]. The lab with more points gets a total reward of 2000 tokens (10 Euros), to be equally distributed among all participants of the winning lab, i.e. each participant gets 200 tokens (1 Euro). In case the two labs achieve the same number of points, the winner is decided randomly (with equal probability).

Participation Game: In Task 3 you will be asked to make decisions in 40 rounds, with one decision per round. You will be part of a group of 5 participants: you and 4 others. The participants that are part of your group are all drawn from [name of the participant's lab]. Group composition will remain constant for the whole of Task 3. Your group will interact with another group of 5 participants, all of them drawn from [name of the other lab]. 
In every round, each member of a group will have to decide on whether to buy a "disc" or not. A "disc" costs 30 tokens. Members of the group with more "discs" receive a higher reward: 120 tokens.

Members of the group with fewer "discs" receive a lower reward: 30 tokens.

If the number of discs in the two groups is the same, the group who gets the higher reward in that round is picked with equal probability. In other words, in case of a tie each group has a $50 \%$ chance of getting the high reward. Note that if one of the groups gets the high reward the other necessarily gets the low reward.

As an example, assume that 3 people in your group buy discs, but only 2 people in the other group buy discs. In this situation, your group gets the high reward in this round. A member of your group who bought a disc gets a payoff of 90 tokens in this round. A member of your group who did not buy a disc gets a payoff of 120 tokens in this round. A member of the other group who bought a disc gets a payoff of 0 tokens in this round. A member of the other group who did not buy a disc gets a payoff of 30 tokens in this round.

Allocation Decisions: We would like to ask you to divide 200 tokens (1 Euro) between a random participant who is part of your group (excluding yourself) and a random participant who is part of the other group. Recall that your group is composed of you and 4 other participants from [name of the participant's lab]. The other group is composed of 5 participants from [name of the other lab].

These amounts will be paid at the end of the experiment. We will randomly select both a member of your group and a member of the other group who will receive your chosen allocation. You will be affected by the choices of two other random participants in the same way. 